\title{
Phytopathology
}

\section{Disease Suppressive Soils: New Insights from the Soil Microbiome}

\author{
Daniel Schlatter, Linda Kinkel, Linda Thomashow, David Weller and Timothy Paulitz ${ }^{\dagger}$
}

First, third, and fourth authors: U.S. Department of Agriculture-Agricultural Research Service, Wheat Health, Genetics, and Quality Research Unit, Washington State University, Pullman 99164-6430; and second author: Department of Plant Pathology, University of Minnesota, St. Paul 55108.

Accepted for publication 9 June 2017.

\begin{abstract}
Soils suppressive to soilborne pathogens have been identified worldwide for almost 60 years and attributed mainly to suppressive or antagonistic microorganisms. Rather than identifying, testing and applying potential biocontrol agents in an inundative fashion, research into suppressive soils has attempted to understand how indigenous microbiomes can reduce disease, even in the presence of the pathogen, susceptible host, and favorable environment. Recent advances in next-generation sequencing of microbiomes have provided new tools to reexamine and further characterize the nature of these soils. Two general types of suppression have been described: specific and general suppression, and theories have been developed around these two models. In this review, we will present three examples of currently-studied model systems with features representative of specific and general suppressiveness: suppression to take-all (Gaeumannomyces graminis var. tritici), Rhizoctonia bare patch of wheat (Rhizoctonia solani AG-8), and Streptomyces. To compare and contrast the two models of general versus specific suppression, we propose a number of hypotheses about the nature and ecology of microbial populations and communities of suppressive soils. We outline the potential and limitations of new molecular techniques that can provide novel ways of testing these hypotheses. Finally, we consider how this greater understanding of the phytobiome can facilitate sustainable disease management in agriculture by harnessing the potential of indigenous soil microbes.
\end{abstract}

Suppressive soils provide the best examples of natural microbebased plant defense, whereby via rhizodeposition plant roots stimulate, enrich, and support soil microorganisms as the first line of defense against soilborne pathogens (Weller et al. 2002, 2007). They are soils in which, because of their microbial makeup and activity, a pathogen does not establish or persist, establishes but causes little or no disease, or establishes and causes disease at first but then the disease declines with successive cropping of a susceptible host even though the pathogens may still persist in the soil (Baker and Cook 1974; Cook and Baker 1983; Weller et al. 2002). Suppressive soils owe their activity to a combination of "general" and "specific" suppression. General suppression is the ability of soils to inhibit the growth and activity of soilborne pathogens to some extent, owing to the collective competitive and antagonistic activity of the total soil microbiome competing with the pathogen(s) (Cook 2014; Weller et al. 2002). We define the microbiome as a community of microbes in a particular environment (in this case the soil and rhizosphere), which includes not only their genes, but their transcripts, metabolites and proteins. General suppression is a natural and preexisting characteristic of soil; is often effective against a broad spectrum of

${ }^{\dagger}$ Corresponding author: T. Paulitz; E-mail: timothy.paulitz@ars.usda.gov

This article is in the public domain and not copyrightable. It may be freely reprinted with customary crediting of the source. The American Phytopathological Society, 2017. soilborne diseases; is not transferrable from field to field or soil to soil with very small amounts of microbial inoculum or soil; is reduced by steaming and eliminated by sterilizing the soil; and can be enhanced by management practices that increase the population size, diversity and/or activity of the soil microbiome (Baker and Cook 1974; Cook 2014; Cook and Baker 1983; Weller et al. 2002). It is important to remember that most soilborne pathogens exist primarily as dormant structures, waiting for root or seed exudates or added nutrients to stimulate and fuel germination, growth and root infection. Cook (2014) equates general suppression to a microbial fire that is "burning" root exudates and other nutrients and limiting their availability to soilborne pathogens. Thus, general suppression is manifested as a continuum of suppressiveness, and the faster the burn rate from increased microbial activity, the greater the general suppression limiting pathogen growth and infection. General suppression is easily visualized and quantified when inoculum of a soilborne pathogen is added to an unamended or raw field soil and to the same soil that has been sterilized. Less disease develops on the host plant in the raw compared with the sterilized soil (Weller et al. 2002), and the amount of suppressiveness can be quantified by calculating the difference in disease incidence or severity between the two soils. Soils that express only this "basal level" of general disease inhibition are considered "conducive" or "nonsuppressive" soils when compared with soils with specific suppression.

In their first book on biological control, Baker and Cook (1974) highlighted how general suppression can sometimes be significantly 
enhanced to a very high level comparable to that observed for specific suppression. An excellent example was the control of Phytophthora root rot in an avocado grove established in the early 1940s in Queensland, Australia, which remained healthy after more than 40 years despite growing in soil infested with Phytophthora cinnamomi in an environment highly favorable for disease development. In contrast, Phytophthora root rot was severe in neighboring groves. Suppressiveness was associated with soil organic matter, maintained at about $12 \%$ by adding large amounts of biomass such as chicken manure, corn stalks, and other plant materials, which stoked the "microbial burn." Essentially, the orchard was managed organically and the soil was described as a "really live soil" based on the diversity and size of the microbial biomass (Cook 2014). However, this general suppressiveness was not transferable, and it was overcome by adding large quantities of pathogen inoculum (Baker and Cook 1974). More recently, the application of specific amendments to enrich a more limited part of the microbiome such as Streptomycetes (see below) (Klein et al. 2013; Mazzola et al. 2007; Tomihama et al. 2016; Wiggins and Kinkel 2005a, b) is receiving considerable attention as a means to enhance general suppression. However, just as with the suppression of Phytophthora root rot, this type of suppressiveness is not transferable by transferring small amounts of soil.

Specific suppression is superimposed over a background of general suppression. Historically, specific suppression is what was envisioned when discussing disease-suppressive soils. More recently however, many studies of suppressive soils, and especially those focused on the soil or rhizosphere microbiome using nextgeneration sequencing, often address general suppression rather than specific suppression. It is important to reiterate that suppressiveness functions as a continuum from general to specific, with the former underlying and potentially giving rise to the latter over time and in response to certain cropping practices (Cook 2014). Specific suppression is highly effective; it results from individual species or select groups of microorganisms; is transferable by adding pure cultures or very small amounts ( 1 to $10 \%$ ) of suppressive soil to a conducive soil; and generally is eliminated by pasteurization at 55 to $60^{\circ} \mathrm{C}$ for $30 \mathrm{~min}$ (but there are exceptions to this; Cha et al. 2016) or by fumigating (methyl bromide) the soil (Cook and Rovira 1976; Gerlagh 1968; Shipton 1975; Weller et al. 2002). Transferability by adding a small amount of soil or inoculum of the responsible microbial species is the key characteristic that separates specific suppression from general suppression. Or put another way, there is no dose response in specific suppression. A similar level of suppression is ultimately generated by transferring 1 or $10 \%$ to a conducive soil. Because specific suppression is due to a population rather than a community, it does not take much for that population of a specific organism to become established in its niche, whether it be a diseased root in the case of take-all decline, or a fungal host in the case of a mycoparasite.

Some soils with specific disease suppression are characterized as "long standing" because the suppressiveness is naturally associated with the soil, its origins are not known, and suppressiveness persists in the absence of plants (Weller et al. 2002). One of the best examples of long-standing suppression occurs in certain soils from the Chateaurenard region of France, which have long been known to be highly suppressive to Fusarium wilts of several crops (Alabouvette 1986). Other suppressive soils are "induced," meaning that specific suppressiveness is initiated and sustained by crop monoculture, by growing crops susceptible to the disease, or by adding inoculum of the pathogen into the soil (Hornby 1983, 1998; Weller et al. 2002). The best described example of induced specific suppression is takeall decline, which is "induced" by wheat or barley monoculture following a severe outbreak of take-all (Weller et al. 2002). Soils with specific suppressiveness against fungi, oomycetes, bacteria, and nematodes occur worldwide (Weller et al. 2002). The mechanisms of specific (and general) suppression have not been fully defined for most suppressive soils.
For scientists new to the field of disease-suppressive soils, it can be challenging to visualize how specific suppression can result from the activity of individual or select groups of microorganisms given the enormous diversity of species in the soil microbiome. However, this is not to say that the total microbiome does not contribute to specific suppressiveness; it just is not the key player. Perhaps the best argument against the primary role of microbial communities and microbiome diversity in specific suppression lies in the ability of $1 \%$ or less volume of a suppressive soil or the addition of the specific microbe(s) responsive for suppressiveness to rapidly convert a conducive soil to a state of specific suppressiveness (Cook and Baker 1983; Cook and Rovira 1976; Weller et al. 2002) under either controlled or field conditions. This suggests that the conditions for the rapid buildup of the specific suppressiveness are very strong in the presence of disease or a specific target for the suppressive organism (s), such as a fungal host in the case of a mycoparasite. One would expect that competitive exclusion would prohibit the microbiome in the one part suppressive soil from rapidly converting the 99 parts conducive microbiome after only one or two cropping seasons of a host susceptible to the target pathogen. On the other hand, there are numerous examples in which individual antagonistic strains of bacteria or fungi with an affinity for a host crop or pathogen propagule reach threshold population sizes $\left(10^{5} \mathrm{~g}^{-1}\right.$ root tissue) and initiate sustained disease suppression (Raaijmakers and Weller 2001; Weller et al. 2007). A classic example is the natural suppression of crown gall, caused by Agrobacterium tumefaciens. The observation of over 40 years in South Australia (New and Kerr 1972) that the incidence of crown gall on almond correlated with the ratio of pathogenic to nonpathogenic agrobacteria suggested the ability of a single bacterial species, A. radiobacter (nonpathogenic), to suppress a disease. This resulted in the development of one of the most successful biocontrol agents, strain K84. This phenomenon has since been seen in other orchards (Lamovšek et al. 2014). Specific suppressive microorganisms often directly attack the pathogen (i.e., Dactylella oviparasitica against the beet-cyst nematode Heterodera schachtii) (Olatinwo et al. 2006) and/or show intimate niche overlap with the pathogen especially in infection courts (i.e., A. radiobacter and A. tumefaciens; $P$. brassicacearum and Gaeumannomyces graminis var. tritici; pathogenic and nonpathogenic F. oxysporum) (Alabouvette 1986; New and Kerr 1972; Weller et al. 2007).

In this review, we will present three currently studied model systems with features representative of specific and general suppressiveness. Based on these systems, we will consider hypotheses about the fundamental nature of specific and general disease-suppressive soil microbial communities, explore and critique ways in which new tools provide novel ways for testing the hypotheses, and finally, consider how the resulting insights can help to guide progress in phytobiome-based sustainable disease management, a goal critical to harnessing the potential of indigenous soil microbes to provide pathogen suppression in agriculture.

\section{MODEL SUPPRESSIVE SOIL SYSTEMS}

Take-all. Take-all, caused Gaeumannomyces graminis (Sacc.) von Arx \& Olivier var. tritici Walker, continues to be an important root diseases of wheat worldwide (Cook 2003). Take-all is most severe when wheat is grown in areas with high precipitation or under irrigation (Cook 2003; Freeman and Ward 2004); however, it can also occurs under dryland conditions (Cook 2003). The pathogen survives as mycelium in dead roots and tiller bases and also in the roots of native grasses and volunteer cereals, all of which serve as inoculum sources for the next crop of wheat (Cook 2003; Paulitz et al. 2002; Freeman and Ward 2004). Dark runner hyphae growing on the root surface are the source of primary infection of seedlings, and then hyaline hyphae penetrate into the cortex and colonize the vascular tissue, ultimately causing characteristic black lesions. Runner hyphae will continue to grow over the root surface, to other 
roots, and upward to the crown and stem bases if moisture is sufficient. Early infection often results in yellowing of lower leaves, stunting, and premature death of plants in patches. Crop rotation and tillage are approaches to manage take-all, but trends are away from those practices in modern farming systems. Wheat cultivars lack resistance to take-all, but cultivars differ in ability to build up inoculum of G. graminis var. tritici (McMillan et al. 2011), opening the possibility of reducing the risk of disease in a second wheat crop by growing a cultivar that reduces inoculum buildup. Methods of chemical control have had only moderate success in controlling the disease (Cook 2003).

Take-all decline. Take-all decline (TAD), one of the bestcharacterized examples of induced-specific suppression, is defined as the spontaneous reduction in the incidence and severity of takeall and increase in yield occurring with continuous monoculture of wheat or barley following a severe attack of the disease (Hornby 1998; Weller 2015; Weller et al. 2002). TAD was first described over 70 years ago, is considered to be a field phenomenon, and occurs globally (Kwak and Weller 2012; Weller et al. 2002). The similarity with which TAD occurs throughout the world is remarkable considering the wide range of climates, agronomic conditions, and soil types under which wheat is cultivated. TAD is used by growers to manage take-all, and in the Pacific Northwest (PNW) of the United States. Cook (2003) estimated that about 0.8 million hectares of wheat suffer little damage from take-all due to TAD (Cook 2003).

The development of TAD follows a consistent pattern everywhere, but cropping history, environmental conditions, and soil factors will impact the intensity (robustness) of the suppressiveness as well as the length of time before its onset, which typically averages 4 to 6 years (Kwak and Weller 2012; Weller 2015; Weller et al. 2002). TAD suppressiveness can be transferred to conducive soils in both the field and the greenhouse by adding 1 to $10 \%$ suppressive soil (Cook 2007; Raaijmakers and Weller 1998; Weller et al. 2002). Suppressiveness is eliminated by treating the soil by pasteurization with moist heat $\left(60^{\circ} \mathrm{C}\right.$ for $\left.30 \mathrm{~min}\right)$ or fumigation with methyl bromide or chloropicrin (Raaijmakers and Weller 1998; Weller et al. 2002), and reduced or eliminated by growing a nonhost crop (Weller et al. 2002), but a TAD field regains suppressiveness once wheat or barley is again grown. Thus, TAD soil remains "primed" for suppression even when monoculture is interrupted. This resiliency was demonstrated when a TAD soil from Lind, WA that was stored dry in cans for over 25 years was readily reactivated by planting only two cycles of wheat in the greenhouse (Allende-Molar 2006).

Microbial basis of TAD. Changes in the soil or rhizosphere microbiome resulting in inhibition of G. graminis var. tritici have long been reported as mechanisms of TAD (Hornby 1998; Sanguin et al. 2009; Weller et al. 2002). Because microorganisms from many different genera have biocontrol activity against take-all and G. graminis var. tritici is highly sensitive to different forms of antagonism (Weller et al. 2002), different antagonist species have been suggested to be responsible for TAD (Kwak and Weller 2012). However, there is abundant microbiological and biochemical evidence for a key role in TAD of fluorescent Pseudomonas spp. that produce the antibiotic 2, 4-diacetylphloroglucinol (DAPG) in at least the PNW (Raaijmakers and Weller 1998; Raaijmakers et al. 1997), in fields throughout the United States (Landa et al. 2006; McSpadden Gardener et al. 2000) and in The Netherlands (de Souza et al. 2003). DAPG producers naturally occur in wheat soil microbiomes at low densities. The occurrence of high precipitation or irrigation is ideal for take-all development (Mavrodi et al. 2012), and infection of wheat roots by G. graminis var. tritici initiates an enrichment of DAPG producers (a cycle that is repeated during monoculture) to a density above $10^{5} \mathrm{CFU} \mathrm{g}^{-1}$ root, the threshold required for take-all control (Raaijmakers et al. 1999; Weller et al. 2002, 2007). TAD is an example of how classical and molecular approaches (prior to next-generation sequencing technology) were used to elucidate the microbial basis of take-all suppression. The lines of evidence leading to the conclusion that DAPG producers were responsible for TAD, provide a model for elucidating the microbial basis of other specific suppressive soils.

i. DAPG producers were consistently detected on roots of wheat grown in TAD soils at population densities above the threshold level required for take-all control $\left(10^{5} \mathrm{CFU} \mathrm{g}^{-1}\right.$ root $)$, but were below the threshold or not detected on roots from homologous conducive soils (Landa et al. 2006; Raaijmakers and Weller 1998; Raaijmakers et al. 1999).

ii. Pasteurization of TAD soils with moist heat eliminated both DAPG producers and suppressiveness (Raaijmakers and Weller 1998).

iii. Adding 10\% TAD soil to conducive soils established populations of DAPG producers above the threshold needed for take-all control and transferred suppressiveness to the conducive soils (Raaijmakers and Weller 1998).

iv. Cultivation of oats, a crop that reduces suppressiveness, reduced the population size of DAPG producers below the threshold required for take-all control (Raaijmakers and Weller 1998).

v. Introduction of a DAPG producer from a TAD soil (Raaijmakers and Weller 1998, 2001), but not its DAPG-deficient mutant (de Souza et al. 2003), into conducive soils at low doses suppressed take-all equivalent to the level occurring in TAD soils.

vi. DAPG is highly active against G. graminis var. tritici $(90 \%$ effective dose value ranging from 3.1 to $11.1 \mu \mathrm{g} \mathrm{ml}^{-1}$ ) and the antibiotic acts on multiple basic cellular processes in the pathogen (Kwak et al. 2009, 2011).

vii. The level of disease suppression is positively related to the sensitivity of the G. graminis var. tritici isolate to the antibiotic (Kwak et al. 2012; Mazzola et al. 1995).

viii. DAPG was isolated from roots of wheat grown in TAD soil but not from roots grown in a homologous conducive soil (Raaijmakers et al. 1999).

Diversity among DAPG producers. There is significant genetic diversity among DAPG producers (Weller et al. 2007) in the P. fluorescens complex (Loper et al. 2012). Studies primarily of U.S. isolates initially described 22 genotypes (designated A-T, PfY, and PfZ) (De La Fuente et al. 2006; Landa et al. 2002, 2006; McSpadden Gardener et al. 2000, 2005; Weller et al. 2007). Other studies focusing on European isolates revealed additional diversity (BergsmaVlami et al. 2005; Frapolli et al. 2008; Picard and Bosco 2003), and these estimates of diversity are likely underestimates (Sekar and Prabavathy 2014). In PNW TAD soils, D-genotype strains comprise 60 to $95 \%$ of the DAPG producers on wheat and barley roots (Raaijmakers and Weller 2001) and they colonize better than other genotypes (Raaijmakers and Weller 2001). In addition, many U.S. TAD soils also are dominated by D genotypes (McSpadden Gardener et al. 2000). For example, in a field in Fargo, ND cropped continuously to wheat since 1882, DAPG producers were above the threshold population size and 77\% were D genotype (Landa et al. 2006). Collectively, these findings suggest that D-genotype strains play a dominant role in TAD even though other genotypes occur in PNW TAD fields (McSpadden Gardener et al. 2000; Weller et al. 2007).

Whole genome sequencing has brought more clarity to diversity within the DAPG-producing pseudomonads (Loper et al. 2012), placing them into at least three species: P. fluorescens, P. protegens, and $P$. brassicacearum. D-genotype strains are now recognized as P. brassicacearum (Achouak et al. 2000; Belimov et al. 2007) and include well-studied strains Q8r1-96, L5.1-96, and Q65c-80, all from Washington TAD soils. Most interesting is that $P$. brassicacearum can be a quasi-pathogen of tomato, causing chlorosis, browning, and necrotic lesions in plant wounds inoculated with the bacteria (Belimov et al. 2007; Sikorski et al. 2001; M.-M. Yang and D. M. Weller, unpublished data).

Crop preference. The wheat rhizosphere contains thousands of microbial species, provoking a question as to how one genotype of 
the P.fluorescens "complex" can be responsible for such a powerful natural suppression of take-all. The answer may lie in the mutual affinity of this bacterium and wheat roots. This affinity enables $P$. brassicacearum to aggressively colonize the wheat rhizosphere far better than other genotypes in the microbiome and to maintain threshold densities throughout the growing season (Raaijmakers and Weller 2001; Weller et al. 2007). Of the genotypes of DAPG producers described so far, several besides genotype D strains have shown a similar type of crop preference (Weller et al. 2007). For example, P- and K-genotype isolates have an affinity for pea (Landa et al. 2002) and wheat (Landa et al. 2003), respectively. The ability of the crop species to enrich for specific genotypes is strikingly demonstrated in two adjacent wheat and flax fields in Fargo, North Dakota (Landa et al. 2006). In contrast to the wheat field enriched in P. brassicacearum, the rhizosphere of continuous flax grown since 1894 is enriched Fand J-genotype strains (41 and 39\%) (Landa et al. 2006).

Intensity of suppressiveness in TAD soils. Despite decades of research on TAD, knowledge gaps still exist as to the conditions that promote specific enrichment of DAPG producers on wheat, the basis for variation in the length of time required before TAD onset, fluctuations in the robustness of suppressiveness among fields and years, and longer-term breakdowns of suppression (Hornby 1998; Kwak and Weller 2012). Kwak et al. (2009) addressed the question about whether development of tolerance to DAPG in G. graminis var. tritici isolates could explain variation in the robustness of suppressiveness among fields. Although $G$. graminis var. tritici isolates within a given field differed in antibiotic sensitivity, those from TAD and conducive fields did not differ significantly (Kwak et al. 2009). It is not likely that G. graminis var. tritici will develop tolerance in the field because the antibiotic attacks basic cellular pathways such as membrane permeability, reactive oxygen regulation, and cell homeostasis in the pathogen (Kwak et al. 2011).

Another factor in the variation in time for onset of TAD and the robustness of suppressiveness could be the differential ability of wheat cultivars to initiate and sustain take-all suppressiveness. Wheat cultivars and crop species differ in how well they support DAPG-producing pseudomonads, DAPG production (Kwak et al. 2012; Mazzola et al. 2004; Notz et al. 2001) and the expression of plant defense genes in response to colonization by DAPG producers (Maketon et al. 2012). At this time, we know of no wheat breeding program focused on improving the supportiveness of cultivars to microbes involved in natural disease suppressiveness. This is certainly an area with tremendous potential for enhancing the consistency and effectiveness of TAD and soil suppression in other systems.

Conclusion. If the rhizosphere holds the key to the next Green Revolution, whereby the development of innovative new varieties and management practices will allow plants to be far more capable of recruiting and utilizing beneficial microbes in the soil microbiome for growth promotion and disease defense, then $\mathrm{T}$ soils like those in TAD are models for elucidating how roots signal, enrich, and sustain beneficial microbes that come to the aid of plants under pathogen attack.

Natural suppression of Rhizoctonia. Rhizoctonia solani (syn. Thanatephorus cucumeris) is a basidiomycete in the order Cantharellales, family Ceratobasidiaceae. This fungus is really a large species-complex of genetically distinct anastomosis groups (AGs) that are classified based on their ability to fuse with vegetatively compatible members of the same group and exchange dikaryotic nuclei. Presently, 13 AGs have been described (Carling et al. 2002), which vary from having narrow (AG-3 on Solanaceae) or wide (AG-4) host ranges. These pathogens primarily cause root rots, damping-off, and rots of below-ground storage organs (tubers). They do not form true spores, they survive by forming sclerotia or dark thick-walled monilioid hyphae that can survive in plant residue. The sexual basidiospore stage is rare in most AG-groups (except AG-1, which causes leaf blights on soybeans and corn). There are cases for which natural suppression of this disease has been well documented: AG-8 on wheat, AG-2-2 on sugar beets.

R. solani AG-8 in Australia. AG-8 causes bare patch and root rot of wheat. First discovered in Australia in the 1930s (MacNish and Neate 1996), the disease is characterized by irregularly shaped patches meters in diameter that suffer complete yield loss. The clearly defined patches caused by AG- 8 simplify assessment of the spatial and temporal distribution of bare patch. The disease became much more severe following the wide adoption of no-till in Australia in the 1970s. With direct-seeding, the crop is planted directly into the previous year's residue or stubble.

In South Australia, at a site near Avon, Rhizoctonia bare patch development decreased after 5 years of continuous no-till wheat and essentially disappeared after 10 years. The suppression was present across a wide range of soils (Roget et al. 1999), was biological in nature (Wiseman et al. 1996), involved either mesofauna or macrofauna (Gupta and Dumitrescu 1999), and was associated with long-term input of carbon in conservation tillage systems. Culture-based methods suggested that suppression resulted from an interaction between three phylogenetically distinct groups of bacteria, Pantoea agglomerans, Exiguobacterium acetylicum, and Microbacteria (Barnett et al. 2006). Similar soils suppressive to Rhizoctonia were found in Western Australia (MacNish 1988).

With the development of next-generation sequencing techniques in the late 2000s, a group of researchers attempted to further characterize these microbial communities at the Avon site and a nonsuppressive site at Minnipa (Penton et al. 2014). This work concentrated on fungal communities and used both pyrosequencing to characterize the amplified DNA of the 28S large subunit (LSU) rRNA genes and TRFLP (terminal restriction fragment length polymorphism). Xylaria, Bionectria, and Eutypa were more abundant in the Avon suppressive soil at two time points, and the nonsuppressive Minnipa soils were dominated by Alternaria and Davidiella (Cladosporium). Gibberella (Fusarium) was one of the most abundant genera in both the suppressive and the conducive soils, and only a small percentage of genera were shared in all four samples. Penton et al. (2014) postulated that Hypocreales and fungi with plant pathogen-suppressive potential were more frequently associated with suppression, although such generalizations are difficult to prove with only correlative evidence. The work was also limited by the fact that it was only done for one year, with only two sampling time points, each from a different part of the soil (bulk soil for the early sample and rhizosphere for the later sample). Even so, the differences in the abundance of fungal genera were not especially dramatic. Another limitation was the taxonomic resolution of the 28S LSU sequencing compared with ITS sequencing with pyrosequencing. Even at the level of genus, there may still have been considerable diversity that was not detected.

In another study, Donn et al. (2014) examined the role of bacteria in Rhizoctonia suppression by using both a 16S rRNA microarray focused on bacteria and T-RFLP to detect bacterial and fungal communities. Asaia spp. and Paenibacillus borealis were present in the Avon suppressive soil, but absent from a paired nonsuppressive site (Galong). Pseudomonas was more abundant inside active disease patches than outside of patches in Galong, but the correlation was not seen at the Harden site, another nonsuppressive site. Variovorax and Oxalobacteriaceae were also higher inside than outside of patches in Galong. Suppression could not be transferred from Avon to Galong, possibly because of different soil types. Bacterial and fungal communities did not differ inside and outside of patches in Galong. However, in stubble retention (direct-seeded plots), they saw differences between fungal and bacterial communities inside and outside of patches. There was no evidence of specific suppression in the Galong site based on transferability in greenhouse bioassays, suggesting a more general nonspecific suppression operating due to the addition of carbon to the system. The use of the microarray was another limitation of the study because microarray techniques survey only a small fraction of the total diversity that can be analyzed with sequencing techniques. 
Wheat plants were grown in soils from 20 Australian locations including the Harden site, rhizosphere soil DNA was extracted, pyrosequenced with bacterial $16 \mathrm{~S}$ rRNA primers, and tested with primers for DAPG and phenazine antibiotic synthesis genes. The Harden site was the only one with DAPG producers, and it also had significantly more abundant Flavobacterium, Oxalobacteriaceae, and Enterobacteriaceae than the others. Two sites with high levels of Rhizoctonia on the Eyre Peninsula in South Australia also showed much higher abundance of Oxalobacteriaceae and Pseudomonas than the others (Paulitz et al. 2012).

Suppression of $\mathrm{R}$. solani in the PNW. R. solani AG-8 was discovered in the PNW (Weller et al. 1986) in the mid-1980s, when direct-seeding was just becoming more widespread in the area. Several lines of evidence, much of it from a site near Ritzville, WA, indicate that Rhizoctonia decline can occur in the PNW. In a longterm rotation study initiated in 1998 on a conventionally tilled farm that was converted to direct seeding at the initiation of the experiment, Rhizoctonia patches began to appear after the second year and were mapped by high resolution GPS over 12 years. The patch area peaked in year seven and since then has declined significantly (Schillinger and Paulitz 2014). Soil cores from the center of patches, patch margins, and outside of patches were planted monthly with cycles of barley for more than nine months in the greenhouse. Barley initially was stunted in all cores from the center of the patches, but in over half of those cores the barley was healthy by the end of the study (Paulitz et al. 2003).

For two years while the patches in plots of continuous wheat were declining, rhizosphere and bulk soils were sampled from inside of patches, outside of patches, and from patches that had disappeared or recovered (Yin et al. 2013). Acidobacteria and Gemmatomonas were present at higher frequencies in healthy areas outside of patches and Dyella and Acidobacteria group 7 were more prevalent in the recovered patches, but the most interesting bacterial groups were those consistently more abundant on diseased roots (rhizosphere) inside of patches: Flavobacterium, Chryseobacterium, Chitinophaga, Pedobacter, and members of the family Oxalobacteriaceae. These same trends with Flavobacteria were verified in the field by qPCR. To determine whether this phenomenon could be reproduced in the greenhouse, soil from an adjacent conventionally tilled field was inoculated with $R$. solani AG-8 and cycled with successive plantings of wheat. As expected, the wheat was stunted in the first cycle but by the third cycle it was healthy, and pyrosequencing confirmed the increase in Flavobacterium and members of the Oxalobacteraceae in the rhizosphere. As a final proof of concept, a "Koch's postulates" experiment was performed with Chryseobacterium soldanellicola strains isolated from the diseased roots. In a greenhouse bioassay with inoculated soil, these strains showed biocontrol ability and significantly reduced disease. This study is among the first to have gone beyond simple correlative associations to demonstrate that a specific organism identified by community analysis could actually suppress disease. However, it remains to be determined whether suppression also may involve interactions with additional taxa or microbial networks.

The data from Rhizoctonia suppression in Washington State were later analyzed by network analysis, which uses correlation and other statistical techniques to group operational taxonomic units (OTUs) into nodes connected by links of positive or negative associations (Poudel et al. 2016). Visualization of correlations in the microbiome data using network analysis (Poudel et al. 2016) revealed three large nodes were associated with rhizosphere bacteria in diseased patches, rhizosphere bacteria from healthy plants, or bulk soil in areas of healthy wheat. This networking technique allows the visualization of groups that may not be evident by other techniques, but it is only based on correlations which may result from interactions among organisms or because multiple organisms may adapt to a similar niche.

Rhizoctonia AG 2-2 on sugar beets. Rhizoctonia causes patches in sugar beets, but unlike those in wheat, they do not seem to occur in the same place from year to year. Anees et al. (2010) inoculated a field with AG-2-2 and found higher inoculum levels of the pathogen inside patches by using qPCR. Communities inside and outside of the patches were characterized using Biolog and T-RFLP of the ribosomal $16 \mathrm{~S}$ and $18 \mathrm{~S}$ genes for bacteria and fungi, and no differences were found between bacterial communities, but fungal communities differed inside and outside of the patches. More Rhizoctonia and Trichoderma were found inside of the patches, and a number of the Trichoderma isolates showed biocontrol activity. However, only about 300 fragments for fungi and bacteria were identified, yielding much less taxonomic depth than obtained with sequencing techniques.

A technique developed before pyrosequencing is an oligonucleotide microarray based on $16 \mathrm{~S}$ rRNA genes. Called the PhyloChip, this approach can give a better depth of taxa than T-RFLP. Using a 16S rRNA oligonucleotide microarray Mendes et al. (2011) found that $\gamma$ and $\beta$-Proteobacteria were associated with suppression. They were able to isolate and characterize suppressive Pseudomonas spp. that produced a lipopeptide with antifungal activity. Biological control activity of the strains was abolished when a gene in the lipopeptide biosynthesis pathway was inactivated. Using the same suppressive soil system, Chapelle et al. (2016) found that a few specific transcripts that were more highly associated with inoculated treatments (HtrA/Sec secretion systems, guanosine-3,5-bispyrophosphate ((p)ppGpp) metabolism, and oxidative stress response), which led the authors to suggest a model in which bacteria on diseased roots respond to oxidative stress generated by the pathogen and oxalic acid.

Conclusions. A unified theory of Rhizoctonia suppression remains elusive. Part of the difficulty is that various studies have focused on either fungal or bacterial communities and also used techniques that are difficult to compare. Some research groups assume that the interaction with the pathogen occurs in the infection court- the rhizosphere-and because of the well-known rhizosphere effect, these studies have focused on bacteria and the involvement of antibiosis. Indeed, there is a growing body of evidence that diseased roots support a unique bacterial community antagonistic to the pathogen and consisting of copiotrophs such as the Oxalobacteriaceae, Pseudomonadaceae, and Sphingobacteriales such as Flavobacterium and Chryseobacteria. The leaky roots attacked by Rhizoctonia may provide an ideal carbon source for these bacteria. But is this a type of specific suppression? Or is it a form of general suppression based on carbon inputs and microbial activity, as suggested by Donn et al. (2014)? Or do fungal communities influence the survival of Rhizoctonia in sclerotia or infected roots, or interfere with hyphal growth through the soil prior to infection?

Streptomyces in plant disease suppression. Streptomyces lifehistory and their interactions with plants and microbes. Streptomycetes, Gram-positive actinomycetes, are predominantly soil saprophytes and found ubiquitously in soils, sediments, and other environments throughout the globe (Seipke et al. 2012). Streptomyces synthesize many siderophores and degradative enzymes (e.g., chitinases) to break down complex substrates (Chater et al. 2010; Hjort et al. 2010) and are exceptional producers of a diverse array of antibiotic compounds with wide ranging abilities to inhibit the growth of competitors (Watve et al. 2001). Antibiotic production by Streptomyces is often coupled with their complex developmental cycle, which in turn is triggered by resource availability in the environment (Kieser et al. 2000). Streptomyces grows vegetatively to colonize substrates when resources are abundant, but when resources are depleted, substrate mycelia undergo programmed cell death to feed the growth of aerial reproductive hyphae. Antibiotic production typically occurs at the onset of aerial hyphae formation, and is believed to defend the resources released by the dying substrate mycelia (Seipke et al. 2012). Finally, aerial hyphae differentiate into chains of stress-resistant spores that can survive long periods of time in soil ( $>20$ years). In addition to resource availability, intra- and interspecific signals are critical mediators of Streptomyces differentiation and antibiotic production (Becker et al. 1997; Takano 2006; Traxler et al. 2013; 
Ueda et al. 2000; Wang et al. 2014). Together, the suite of extracellular enzymes and antibiotics are key determinants of Streptomyces fitness and allow them to effectively compete with other microbes in soil through resource and/or interference competition with other microbes including plant pathogens (Hiltunen et al. 2009; Kinkel et al. 2014; Neeno-Eckwall et al. 2001; Williams et al. 1989).

Because of their strong capabilities to compete for plantproduced resources including root exudates and dead plant tissue, Streptomyces form intimate associations with plants and are common colonists of the rhizosphere and endosphere (Cao et al. 2004; Franco et al. 2016; Viaene et al. 2016). The impacts of plantsymbiotic Streptomyces on plant health range from beneficial to pathogenic. Many strains have been described that promote plant growth through the production of plant hormones or solubilization of nutrients, whereas other strains can induce plant resistance or defend plants from pathogens via antibiosis or competitive exclusion (Kinkel et al. 2012; Schrey and Tarkka 2008; Seipke et al. 2012). A small number of Streptomyces species produce thaxtomin phytotoxins and are responsible for economically important plant diseases, including common and acid scab of potato and other tuber crops (Bignell et al. 2014). Thaxtomin, a necessary virulence factor for pathogenic Streptomyces, contributes to disease by inhibiting the synthesis of cellulose, ultimately leading to plant cell death. Thaxtomin production is induced by plant cell wall components, most notably cellobiose (Lerat et al. 2009). The genes responsible for thaxtomin production lie within a pathogenicity island (PAI) that includes a number of other virulence factors including genes for nitric oxide production and secreted proteins (Bignell et al. 2010). The thaxtomin PAI can be horizontally transferred between Streptomyces species, resulting in the emergence of new pathogenic strains (Lerat et al. 2009; Loria et al. 2006).

Natural suppression of potato scab. There are numerous cases of suppression to potato scab developing in response to long-term potato monoculture (Lorang et al. 1989; Meng et al. 2012; Menzies 1959). For example, Menzies (1959) first described an absence of scab symptoms in old fields repeatedly cropped to potato in the Columbia Basin of central Washington State, whereas scab was common in nearby soils with less than 15 years of monoculture. In pot assays in the field, repeated potato plantings in suppressive soil led to scab decline after one crop cycle whereas severe scab occurred after repeated plantings in virgin soils. Similar observations were made in a potato scab plot in Grand Rapids, Minnesota after more than 20 years of monoculture (Lorang et al. 1989), and in East Lansing, Michigan after over 25 years of monoculture (Meng et al. 2012). In each of these cases suppressiveness was transferrable to conducive soil and eliminated by steam or heat treatments. In some cases, such as in Minnesota (N. A. Anderson, personal communication) and in scab-suppressive soils in Eastern Europe (SagovaMareckova et al. 2015), suppression appears to be resilient to rotations with non-potato crops, suggesting the potential for stable, long-term disease suppression.

Kinkel et al. (2012) compared Streptomyces communities from the Grand Rapids suppressive soil and adjacent conducive fields and found that suppressive soils harbored higher frequencies of inhibitory isolates with greater intensities and diversities of antibiotic activities than isolates from conducive soils. Pathogen-antagonistic Streptomyces strains isolated from tubers grown in the suppressive soils were effective colonizers of tubers when reinoculated into conducive soil and significantly reduced potato scab in successive growing seasons (Bowers et al. 1996; Liu et al. 1995, 1996). This work suggests that a buildup of high densities, frequencies, and diversities of pathogen-antagonistic Streptomyces in soil plays a key role in natural suppression of potato scab by acting as a reservoir for a diverse suite of tuber-colonizing antagonists (Ryan and Kinkel 1997; Wanner 2007). However, further work using antibioticresistant $S$. scabies mutants indicated that some Streptomyces strains can reduce $S$. scabies populations even when the pathogen is not sensitive to antibiotic inhibition (Neeno-Eckwall et al. 2001). Thus, both antibiotic inhibition and competition between pathogenic and nonpathogenic Streptomyces are likely to be important mechanisms of natural suppression of potato scab. Recent work using both culture-dependent and -independent methods to compare microbial communities in scab-suppressive soils with communities in adjacent conducive soils in Michigan also suggests that pathogenantagonistic Streptomyces may play a role in disease suppression (Meng et al. 2012; Rosenzweig et al. 2012). However, these studies also implicate other bacterial lineages with known antagonistic activities (fluorescent Pseudomonas, Bacillus, and Lysobacter species). Thus, although research on potato scab-suppressive soils has largely implicated nonpathogenic Streptomyces as the agents responsible for suppression, evidence is accumulating that interactions among a broad range of bacterial and fungal taxa contributes to scab suppression.

Natural suppression of other diseases by antagonistic Streptomyces. Streptomyces are also involved in natural suppression of nonstreptomycete plant pathogens. In soil under a long-term (more than 40 years) cauliflower monoculture that had developed suppression to Rhizoctonia solani AG2-1, Postma et al. (2010) found greater densities of filamentous actinomycetes in suppressive soil versus conducive soils and that Streptomyces comprised a significant portion (21\%) of bacterial antagonists against $R$. solani. In this system, antagonistic Lysobacter species were also implicated as an important component of disease suppression. In a recent investigation of a soil suppressive to Fusarium wilt of strawberry, Cha et al. (2016) found that suppressive soils differed in bacterial community structure and had consistently higher relative abundances of actinomycetes than did conducive soils. Using this information as a guide, a 'representative actinomycete' was isolated and identified as a Streptomyces species. It was demonstrated to have antagonistic activity against $F$. oxysporum, and was also an efficient colonist of the strawberry rhizosphere in the presence of the pathogen. Genome mining and subsequent mutation experiments suggested that this isolate conferred suppression by producing a novel thiopeptide antibiotic that inhibits fungal cell wall synthesis. This study demonstrates the power of novel sequencing approaches for understanding the microbial players involved in disease suppression and the mechanisms by which they protect plants from pathogens.

Amendment-induced suppression by Streptomyces. The use of organic amendments or green manures is often explored as an environmentally friendly means to control soilborne pathogens by selective enrichment for populations of pathogen antagonists (Mazzola 2007). As efficient soil saprophytes, Streptomyces are especially likely to respond to incorporation of organic material into soil, and are often implicated as microbial agents responsible for amendment-induced suppression (Klein et al. 2013; Mazzola et al. 2007; Tomihama et al. 2016; Wiggins and Kinkel 2005a, b). For example, Klein et al. (2013) amended soils with wild rocket (Diplotaxis tenuifolia) to enhance the general suppressiveness to $F$. oxysporum f. sp. radicis-cucumerinum and characterized root-associated microbial communities in relation to suppression. The relative abundance of root-associated Streptomyces was higher in amended (suppressive) soils than in nonamended (conducive) soils. Because this shift also appeared in noninoculated controls, the induced suppression was thought to occur independently of the presence of the pathogen. By examining shifts in the actinobacterial community, these researchers found that a population of $S$. humidus believed to be antagonistic to phytopathogenic fungi dominated root actinobacteria 3 days after amendment. However, other potential antagonists also increased in suppressive soils (Bacillus, Paenibacillus, Rhizobium). Similarly, Tomihama et al. (2016) used rice bran amendments to induce suppression to potato scab. In this system, reductions in potato scab were associated with increases in the relative abundances of Streptomyces. Moreover, most Streptomyces isolated from potatoes after amendment displayed pathogen-antagonistic activity, and many of these reduced scab when reinoculated in field trials. These studies demonstrate the 
role that indigenous, pathogen-antagonistic Streptomyces can play in amendment-induced disease suppression in diverse pathosystems.

Conceptual model for Streptomyces-based disease suppression. Though many attempts have been made to suppress disease directly via inoculation of Streptomyces (biological control) or indirectly through soil amendments, they have generally met with mixed success (Bonanomi et al. 2010; Mazzola 2007). Long-term monoculture appears to provide the most consistent strategy to achieving long-lasting suppression in Streptomyces systems (Lorang et al. 1989; Meng et al. 2012; Menzies 1959; Postma et al. 2010). Consistent with field studies where the densities of pathogen-antagonists in soil were negatively correlated with disease (Wiggins and Kinkel 2005a, b), long-term experimental monocultures in a plant diversity manipulation at the Cedar Creek Ecosystem Science Reserve (a nonagricultural setting) also harbored consistently greater proportions of antagonistic Streptomyces than more diverse plant communities (Bakker et al. 2013; D. Schlatter and L. L. Kinkel, unpublished data). Subsequently, Essarioui et al. (2016) found that Streptomyces isolated from these monocultures had greater similarity in carbon use profiles than those from polycultures, suggesting that resource competition in monocultures selects for highly antagonistic Streptomyces populations. Based on these observations, a model was proposed where resource competition in monocultures drives density- and frequency-dependent selection for antibiotic phenotypes, thus generating highly pathogenantagonistic Streptomyces communities (Kinkel et al. 2011, 2012). Over multiple generations of microbial growth, reciprocal selection for antibiotic inhibitory and resistance traits may generate a coevolutionary 'arms race' among Streptomyces in soil (Kinkel et al. 2014), maintaining both antagonist densities and diversities of antibiotic phenotypes and contributing to sustained, broad-spectrum disease suppression (Kinkel et al. 2012). Recent work shows that additional genera, including members of the genus Fusarium, also exhibit patterns of locally-adapted antagonism against Streptomyces, suggesting the potential for broad-based coevolutionary arms race dynamics among diverse soil saprophytes to contribute to pathogen suppression (A. Essarioui, N. LeBlanc, H. C. Kistler, and L. L. Kinkel, unpublished data). Antagonist Streptomyces may serve as a keystone or indicator taxon that stimulates antagonistic competitive interactions among a broad range of soil taxa, contributing to the capacities of Streptomycesbased suppressive soils to inhibit a broad range of plant pathogens.

Though eco-evolutionary interactions among Streptomyces and other taxa will certainly be critical to generating and maintaining pathogen-suppressive phenotypes, there are significant gaps in our understanding of disease suppression in Streptomyces-based systems. In particular, the molecular bases of disease suppression and the long- and short-term dynamics of Streptomyces intraspecies interactions with other microbiota, with pathogens, and with plants in the rhizosphere remain relatively poorly understood.

\section{THEORIES AND HYPOTHESES ABOUT DISEASE SUPPRESSION: CONTRAST AND COMPARISON OF THE THREE SYSTEMS}

We suggest that the three examples presented here vary along a continuum of specific to general suppression: the highly specific disease suppression of take-all; suppression of Rhizoctonia based on numerous potential antagonists; and scab-suppressive soils that are based on antagonistic Streptomyces that are associated with a broad general capacity to suppress diverse other plant pathogens.

Though these soil communities all suppress disease, we hypothesize that the origin and dynamics of disease suppression vary across the general-specific continuum. It is critical to understand differences in the ecology of general versus specific suppression, and especially the mechanisms by which disease suppressive soil microbial communities develop and the stability and efficacy of disease suppression. The pathways by which agricultural management might reproducibly achieve general or specific disease suppres- sive soil communities represents a critical challenge for researchers. Using these systems as examples/models, we hypothesize specific ecological and evolutionary contrasts between specific and general suppression. Our objective in posing these hypotheses is to stimulate further research to expand our understanding of disease suppressive soil microbiomes, and to accelerate the development of broad, generalizable principles of soil microbiomes in relation to disease suppression.

Specific suppression is population-based; general suppression is community-based. Take-all suppressive soils require shifts in specific antibiotic-producing Pseudomonas populations (Weller et al. 2002). In contrast, while scab-suppression has been investigated primarily in relation to antibiotic-producing Streptomyces, recent work suggests that the accumulation of pathogen-inhibitory Streptomyces populations is accompanied by changes in the densities or inhibitory activities of diverse non-Streptomyces bacterial and fungal populations in soil (Essarioui et al. 2016; Mendes et al. 2011; Meng et al. 2012; Rosenzweig et al. 2012). General suppression is a function of the aggregate capacity of diverse soil microbes to antagonize pathogen populations. However, differences in microbiome composition, structure, and diversity among soils varying in general and specific suppressive capacities remains relatively poorly understood. Understanding the scope of specific populations involved in suppression, or the extent to which suppression is associated with targeted versus broad-based changes in the soil microbiome, is critical because of the potential implications for stability and longevity (see below). More practically, understanding the breadth of community-wide impacts sheds important light on the development of appropriate metrics for detection and quantification of general or specific disease-suppressive capacities in soils. For example, knowledge of the ways in which networks of species interactions in soil microbiomes in the presence of highly-inhibitory populations differ from those with weakly inhibitory populations may be a key predictor of disease suppression. Because general suppressiveness exhibits broad-based capacities to inhibit diverse taxa, including many plant pathogens, the potential for fundamental and 'collateral' shifts in the population structure of the broader soil microbiome is extensive - and these shifts themselves may be significant to both predicting pathogen impacts and to sustained suppression. We suggest that a comprehensive focus on soil microbiome structure, connectivity, and diversity across the range of specific to general disease suppression will provide important clues into the nature of the disease suppressive activity, and to developing predictive metrics for specific and general disease suppression.

The species interactions that generate specific disease or pathogen suppression are different from those that generate general disease suppression. Specifically, pathogen-antagonist interactions generate specific suppression, while antagonist-antagonist interactions generate general suppression. Take-all, Rhizoctonia, and scab-suppressive soils are all a function of monoculture cropping. However, despite apparently similar origins (monoculture), an important contrast between specific take-all suppression and more general scab-suppressive soils is that the development of take-all suppression requires the presence of disease - the pathogen, the susceptible host, and disease-conducive environmental conditions - for enrichment of suppressive populations. In the case of Rhizoctonia, suppression also develops after years of significant disease expression. In contrast, highly antagonistic, scab-suppressive Streptomyces populations can develop with or without a susceptible host or scab disease (Bakker et al. 2012; Schlatter et al. 2015; Weinhold and Bowman 1968). This suggests that selection for specific suppressive capacity within soil microbial communities reflects targeted plant pathogen-antagonist interactions, while general suppression, and scab-suppressive populations in particular, can result from interactions among soil saprophytes that don't depend upon pathogen populations or disease. Rather, selection for general suppressive capacity within soil microbial communities may reflect selection for diverse antagonistic populations within complex networks of species interactions among soil saprophytes. 
What are the implications of distinct species interactions as the origin of different types of disease-suppressive communities? Identifying the particular species interactions that select for pathogensuppressive populations is important for identifying the specific roles of plants, pathogens, soil abiotic characteristics, and saprophytic populations in generating disease-suppressive microbiomes, as well as the ecological, biochemical, and molecular mechanisms that generate a suppressive soil phenotype. Moreover, understanding the species interactions that generate positive selection for pathogen-suppressive populations can also shed light on the fitness tradeoffs or biotic and abiotic conditions that may work against accumulation of pathogen-suppressive populations in soil. For example, are specific suppressive populations that result from diseaseantagonist interactions in the rhizosphere significantly less fit when competing with diverse antagonistic saprophytes composing generally suppressive soil communities, or when present in bulk soil? For take-all or other soils with specific disease suppression, understanding both the fitness benefits of pathogen-suppressive phenotypes in the presence of disease, and the corresponding fitness tradeoffs or costs of those phenotypes in the absence of disease will be critical to developing enhanced management approaches. Similarly, for general suppression, understanding the dynamics of competitive interactions among complex soil populations, and especially how to maintain highly competitive conditions favoring suppressive populations in field soils across distinct management strategies, should be a primary focus of study. Will it be possible to maintain populations having both highly specific and general suppressive capacities in soil microbiomes, or are there significant factors that constrain the capacity to sustain both specific and general suppressive populations across the selection landscape? Fundamentally, understanding which particular species interactions impose selection for suppressive populations, and the conditions under which such populations are likely to have enhanced or reduced fitness, is necessary for focusing research to advance suppressive management.

Selective feedbacks are negative in specific suppressive soils, and positive in general suppressive soils. If different species interactions impose selection for specific versus general suppression, the ecological and evolutionary dynamics of suppression in the two systems will have fundamentally different dynamics. Because antagonists in specific suppression are selected in the presence of a particular pathogen which is sensitive to the antagonist, specific suppression will exhibit a negative feedback dynamic with disease (Fig. 1). Thus, for example, within the take-all system: (i) disease imposes selection for specific pathogen-suppressive population; (ii) pathogen-suppressive population reduces disease frequency and intensity; (iii) there is a loss of positive selection for the diseasesuppressive population; (iv) pathogen-suppressive populations decline; and (v) disease increases. This negative feedback requires continued engagement of the pathogen in selection for the antagonist(s), and results in a continually-cycling selection landscape.

In contrast, in general suppression, with no explicit pathogen role in selection, directional, positive feedbacks in the development and maintenance of antagonistic populations are possible (Fig. 2). Specifically, antagonistic and competitive interactions within the highly diverse network of interacting soil populations may be likely to be self-reinforcing. Competition begets selection for ever-better competitors, so that positive feedbacks may serve to reinforce suppressive potential. In general suppression, pathogen populations suffer apparent collateral damage stemming from competitive interactions within the saprophytic soil microbiome. Note that the competitive dynamics within the community may conceivably induce either arms race or niche differentiation coevolutionary dynamics (or perhaps a combination of both occurring simultaneously). Though these coevolutionary trajectories will yield communities with substantially different functional characteristics (highly antagonistic versus very niche-differentiated), it may be that either one could result in general pathogen suppression through different mechanisms.
However, the pathogens that may be inhibited by highly-antagonistic populations may be quite different from those that are sensitive to strong resource competition (Alabouvette 1986). In either case, positive feedbacks offer the potential for sustained directional selection to maintain and enhance selection for general suppression, in contrast to specific suppressive soils in which intermittent disease/pathogen pressure is required to maintain suppression.

The distinct feedback relationships within specific versus general suppressive populations have significant implications for the development of practical management approaches for optimizing disease suppressive capacities within soil microbiomes. For example, with specific suppression, crop rotation (growing a nonhost) can reduce or eliminate the disease, so acts as a negative feedback to reduce the suppressive capacity of the soil community. This suggests a potential challenge in management to both minimize disease and maximize disease suppressive potential. In the case of general suppression, consideration of pathogen dynamics is less critical to management. Instead, factors that influence antagonist competitive interactions are likely to be much more important to disease suppression. Thus, for example, cover crops or green manures may offer a significant food source that generates positive selection for microbial competitive interactions among microbes able to quickly utilize the substrate. Ultimately, management to enhance suppression will require a clear focus on the distinct interactions that select for disease suppressive populations or communities, and an understanding of the feedback dynamics associated with those selection events.

General suppression may be more stable than specific suppression over time, space, management, crop rotation, and in the presence of disturbance. Stability of disease suppression is an important practical goal. Thus, understanding the sensitivity of pathogensuppressive microbiomes to disturbance or to variation in biotic or abiotic conditions is a key consideration. It could be argued that specific suppression is likely to be less stable over time than general suppression because of the limited breadth and diversity of populations contributing to pathogen suppression and because monoculture must be maintained or the suppressiveness is lost or reduced. On the other hand, to elevate general suppression to a state greater than that found in typical conducive soil, amendments must continually be added to stoke the microbial burn. Diversity is well-established to confer functional stability across a wide range of ecological communities, which would suggest that a diversity of pathogen-suppressive populations will produce more stable function (disease suppression) than a limited collection of antagonists. In suppressive soils, the value of diversity may reflect multiple distinct mechanisms. First, individual antagonistic populations will be much more sensitive to disruptions, and much more variable in densities over time and space, than entire communities. Second, a broad diversity of antagonistic populations engaged in pathogen suppression offers substantial potential for complementarity in activities across a range of biotic and abiotic conditions, and can minimize the likelihood of pathogen 'escape' from suppression. Finally, presence of diverse suppressive populations engaged in distinct means of pathogen suppression will minimize the likelihood that pathogen populations may develop resistance to suppression. Thus, diversity of antagonistic populations within general suppressive soils offers multiple strategies for enhancing the ecological and evolutionary stability of pathogen suppression.

Despite the hypothesized greater stability of general versus specific suppressive soil, there are specific suppressive soils that have been shown to confer long-lasting, stable disease suppression. Thus, in the PNW and across the United States, TAD has effectively suppressed take-all in fields cropped continuously to wheat for decades, and even when wheat monoculture is broken, specific suppression of take-all returns after only one or two crops of wheat. Furthermore, soils from the Chateaurenard region of France have maintained suppressiveness to Fusarium wilts for hundreds of years. This raises intriguing questions about the extent to which specific suppressive populations may have cryptic diversity that sustains their presence 
over fluctuating biotic and abiotic conditions, or whether these populations may have in some cases effectively sidelined the target pathogen population for good. Further investigation of the stability of specific and general suppressive soil microbiomes is needed. Ideally from a grower perspective, a suppressive system should be both stable and able to be rapidly developed.

Biotic and abiotic soil characteristics that influence receptivity to conversion differ for specific versus general suppression. The distinct ecological and evolutionary mechanisms hypothesized to generate specific and general suppressive soil communities suggest important differences in the limiting factors to the establishment of specific versus general suppressive soil communities. In specific suppression, the presence of the pathogen, the susceptible plant host, and environmentally disease-conducive conditions are all required to convert from conducive to suppressive soil. In contrast, general suppression may be more likely to be a function of (bulk) soil nutrient characteristics, coupled with the evolutionary potential (density and diversity) of the soil saprophytic community. Rates of conversion of soil communities to enhanced levels of general disease suppression will be increased by high evolutionary potential within soil microbial communities. In addition, soil nutrient characteristics are significant to general suppression, presumably due to their key role in mediating saprophytic competitive interactions within the soil microbiome. Both high soil organic matter and limited soil nutrient diversity are hypothesized to enhance conversion to increased general suppression due to their direct impacts on total microbial densities and the intensity of competition within the microbiome.

In contrast to general suppression, bulk soil nutrients have apparently little effect on conversion to specific suppression, though rhizosphere nutrient fluxes may be critical factors in ways not yet understood. Similarly, while pathogen populations are not viewed as playing a direct role in enhancing general suppression, pathogens may play indirect roles in mediating the development of general suppression via their impacts on soil nutrient characteristics (e.g., through saprophytic growth or shifts in plant contributions to soil nutrients). Further research on both the soil and rhizosphere nutrient characteristics supporting the conversion or enrichment of general and specific disease-suppressive capacities within soil microbiomes, the relationships between soil community evolutionary potential and conversion dynamics, and the direct and indirect effects of pathogen populations on conversion are needed across a range of general to specific suppressive soil communities.

\section{NEW APPROACHES FOR UNDERSTANDING DISEASE-SUPPRESSIVE MICROBIOMES}

New technologies have made it possible to characterize the composition, functional potential, and activities of microbial communities and their relationships with plants and pathogens at an unprecedented scope and level of detail. Recent DNA-based methods, enabled by highthroughput (HT) sequencing (HTS) of PCR-amplified platforms (e.g., Illumina MiSeq/HiSeq, IonTorrent, PacBio) have revolutionized microbial ecology. Most commonly, profiling of PCR-amplified marker genes (e.g., 16S ribosomal RNA, ITS [internal transcribed spacer], COI [cytochrome oxidase I]) from environmental samples at depths of thousands to hundreds-of-thousands of sequences per sample now allows researchers to efficiently characterize the diversity of microbial communities. As read length, accuracy, and accessibility continue to improve and costs decline, these tools are expected to become routine in the lab and in the field for understanding microbial communities. Network analyses are another tool to provide a means for characterizing and contrasting the structure and connectivity of microbial co-associations among communities having diverse functional characteristics (Poudel et al. 2016).

Despite its power, HT amplicon sequencing has substantial limitations. For example, sampling strategy, DNA extraction, and PCR amplification can introduce significant bias in observed communities (Brooks et al. 2015; Kennedy et al. 2014; Song et al. 2015). Variation in gene copy number among taxa (especially $16 \mathrm{~S}$ rRNA genes) introduces further bias in observed sequence counts, rendering HT amplicon sequencing only semiquantitative (Kembel et al. 2012).

Further, including any relevant metadata, such as soil or environmental characteristics, plant age or health status, or field history, is invaluable in determining the potential drivers of microbial communities and will aid in the development of predictive models for microbial community functional dynamics. Finally, best practices should be followed in every study using HTamplicon sequencing. These include the use of negative and extraction controls free of source material to detect contaminant sequences (Salter et al. 2014), sequencing mock communities alongside samples to quantify sequencing error rates and calibrate clustering thresholds (Nguyen et al. 2015; Schloss et al. 2016), and replicating a subset of samples within and between sequencing runs to examine intra- and interrun variability and bias (Z. Song, D. C. Schlatter, D. M. Gohl, and L. L. Kinkel, unpublished data). Even after generating high quality data, many analytical and statistical challenges remain and care should be taken to use proper normalization procedures and statistical tests for sparse, nonnormal, compositional count data in downstream analyses (McMurdie and Holmes 2014; Paulson et al. 2013; Thorsen et al. 2016; Weiss et al. 2015).

Because HTS data are noisy, sequences are typically clustered into OTUs at a particular similarity threshold (generally 97\%). Numerous approaches for OTU clustering have been developed (Al-Ghalith et al. 2016; Kopylova et al. 2016; Rognes et al. 2016) that fall into three distinct categories based on their reliance on reference databases. Closed-reference OTU clustering simply finds a best match of a query sequence to a reference sequence in a database, but sequences without a match (e.g., uncharacterized taxa) are discarded. De-novo clustering approaches don't rely on a database to define OTUs, and
FIGURE 1

Negative feedbacks illustrated by take-all specific suppression.
Increased disease

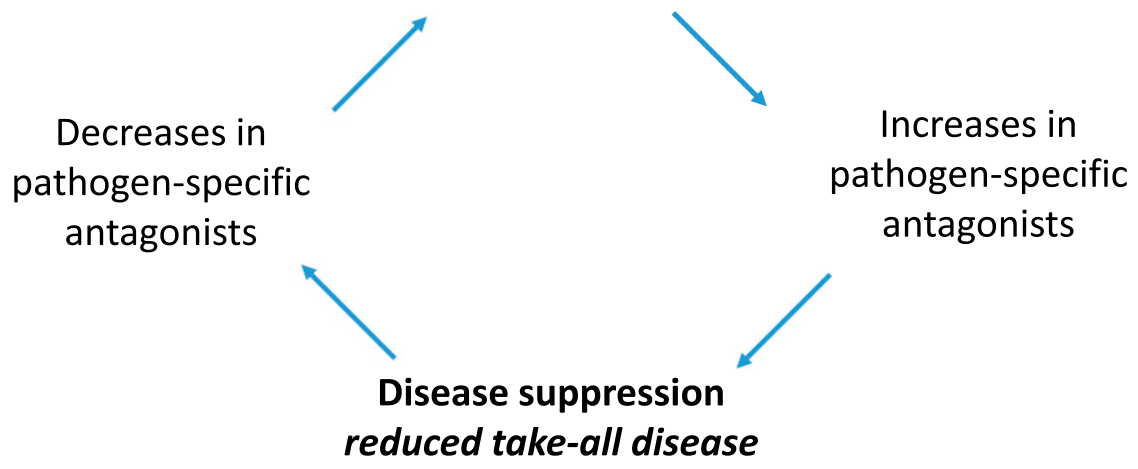


instead cluster all sequences in a dataset relative to one other to generate OTU bins; thus, taxa without representatives in a database will be retained. Open-reference approaches are a hybrid of closedreference and de novo clustering, first relying on hits to a database and then reclustering those sequences failing to hit the database using a de novo approach. Regardless of the algorithm used, OTU clustering at arbitrary similarity thresholds does not necessarily represent biologically coherent units. Due to variation in primer specificity, amplicon length, and evolutionary rates, different markers (e.g., variable regions of the 16S, ITS1, ITS2, 18S, and 28S) have different capacities to detect and delineate taxonomic groups and may resolve some groups while binning others into a single OTU (He et al. 2015; Nguyen et al. 2015, 2016). However, recently developed "denoising" methods may offer robust alternatives to OTU clustering and improved sensitivity to resolve single base pair polymorphisms (Callahan et al. 2016; Edgar 2016). Still, because functional characteristics of microbes such as antibiotic production or resource use can be highly variable within species-groups with identical marker gene sequences, the functional characteristics of an OTU cannot be confidently inferred even with a genus- or species-level taxonomic identification. For example, a Pseudomonas or Streptomyces OTU found in a sample will not necessarily be an antibiotic producer involved in disease suppression. Thus, care must be taken not to over-interpret community sequence data, and patterns found among individual OTUs with hypothetical functions should be confirmed by using complementary approaches for quantifying taxon abundances or functional characteristics (Yin et al. 2013).

Identifying members of a soil microbial community to the genus or species level does not precisely characterize the functional capabilities or activities of the community. Metagenomics, in which all DNA extracted from a sample is sequenced in parallel, can offer additional insight into the diversity and functional potential of microbial communities. Because this technique does not rely on PCR, it lacks primer and amplification biases and can capture a much greater diversity of organisms and genes. Marker genes and functional genes from the same community can be analyzed together to generate a snapshot of community composition and functional potential. Similarly, metatranscriptomics, or the sequencing of RNA transcripts (RNA-seq), provides a snapshot of only the portion of the metagenome that is actively transcribed. However, there are unique analytical challenges for both shotgun metagenomics and meta-transcriptomic data, including metagenome assembly, binning, gene prediction/annotation, and assignment of taxonomy to metagenomics reads (Jiang et al. 2016; Kuske et al. 2015; Sharpton 2014; Zhou et al. 2015). These methods require a much greater sequencing depth to effectively characterize a complex community, and thus they are much more costly to generate and computationally intensive to analyze than amplicon-based community profiles (Howe et al. 2014). Further, as with amplicon profiling, the value of a metagenomic/transcriptomic "snapshot" and the linkages between meta-genomic and transcriptomic information and meaningful soil processes can be unclear (Prosser 2015). For example, treatments that induce subtle changes in community activity may only be apparent in transcriptomes, while not affecting the gene content of a metagenome. In contrast, treatments that impose selection on some taxa will be apparent in marker gene profiling, but combinations of metagenomics and metatranscriptomics will further allow for the identification of not only who is responding, but in what way. Singlecell-omics or fine-scale genomic reconstruction may provide insight

FIGURE 2

Hypothesized positive feedbacks in the development and maintenance of general pathogen suppression. into evolutionary responses of populations. Like other methods, the use of omics tools should be carefully considered in the context of their strengths and limitations to effectively answer a scientific question or hypothesis of interest.

DNA-based methods are only one of many emerging technologies that will be invaluable for dissecting microbiomes of suppressive soils. Recent advances in metabolomics, proteomics, stable-isotopes, and microscopy/imaging not detailed here are proving to be powerful tools for investigating the microbes, genes, and molecules involved in microbial interactions among community members and with plants and pathogens. Combinations of complementary approaches will be especially useful for understanding disease suppressive systems. For example, the metabolism of plant-produced compounds may be tracked through soil food webs using stable isotopes, centrifugation, and HT sequencing (DNA-SIP) (Coyotzi et al. 2016). Integrating new and emerging technologies with traditional approaches will prove powerful for advancing our understanding of suppressive soils (Weller et al. 2002). As new technologies continue to improve the efficiency and scale of sample preparation and the read length and quality of DNA sequencing (e.g., Boreal Genomics Aurora system, $10 \times$ genomics linked reads), we will be able to gain a more detailed and complete characterization of plant and soil microbiomes.

\section{UNDERSTANDING DISEASE SUPPRESSION AS A TOOL FOR DISEASE MANAGEMENT}

Over the last 3 years there has been increasing interest in the concept of "soil health." The year 2015 was the Year of Soil, and 180 papers with the term "soil health" were published in 2016. Companies are marketing tests of soil health such as the Haney et al. (2010) and Solvita tests (Sadeghpour et al. 2016), and growers have become increasingly interested in this concept. These tests are based on organic $\mathrm{C}$ and $\mathrm{N}$, respiration, and biological activity. Most of the measures of soil health have emphasized soil properties, organic matter and general microbial activity. Is this concept of soil health missing the most obvious connection - a healthy soil will be buffered against pathogen activity? Is disease suppression really a more specific manifestation of this concept? Regrettably, as often happens, different disciplines and research communities are not aware of developments and theories from other disciplines. The real question is: how we can capitalize on these soil health concepts to develop management approaches to achieve sustainable production? How can the take-all/Rhizoctonial Streptomyces suppression examples help us think through novel approaches or hypotheses?

In one respect, specific suppression to take-all is already operating across over 800,000 hectares of wheat in the Pacific Northwest (Cook 2003). Rhizoctonia bare patch is primarily seen in this region in early conversion to direct-seed no-till, and there are thousands of acres that have been in long-term no-till without any acute Rhizoctonia problem. But what about growers that have severe disease-how can they enhance and accelerate the development of suppression? How can they reduce the period of conversion from a conducive soil to one harboring microbial populations in a suppressive equilibrium, thus reducing economic losses during the transition period? Can we describe the starting microbial communities and identify those fields that will develop suppression and those that will not? The technology to describe and characterize the microbiome is becoming increasingly less expensive to the point that microbial profiles on a field-by-field basis

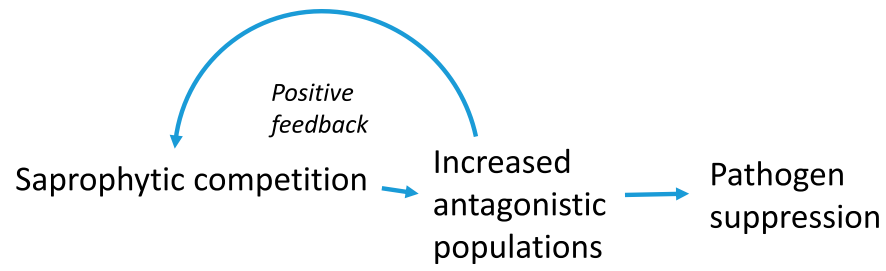


will be available as a commercial service in the near future. In the same way that personalized genomics and microbiomics are now possible in human medicine, will this be the future of agriculture? Or are microbial communities too complex to develop simple predictive models? Will this become the new "snake oil" of agriculture, where over simplistic prescriptions will be offered, based on technology that may be feasible, resulting finally in a solution in search of a problem?

A more direct benefit to growers may be knowledge about how cultural practices can enhance the suppressive capacity of beneficial indigenous microbial populations. For example, how does crop rotation affect the development and sustainability of suppressive populations? With take-all, rotation to a nonhost crop can break the suppression, but the identity of that crop can influence how long it will take to revive suppressiveness when returning to monoculture. In the case of Rhizoctonia, crop rotation may not be as detrimental. In the long-term rotation study near Ritzville, WA, Rhizoctonia suppression of $R$. solani occurred in rotation strips with safflower, mustard, and winter pea (all hosts for the pathogen), raising questions about whether particular cropping sequences might favor the development of suppressiveness. Tillage is another variable that growers might exploit. For example, no-till seems to be important to develop suppression to Rhizoctonia bare patch, possibly because it initially favors disease. Residue management is another cultural practice that can be exploited. Growers use different types of machinery to manage residue and increase its decomposition including flail mowers, choppers, harrows, cultivators, rakes, and sickle bars and chaff spreaders on combines. Does crop residue play a role in suppression?

We know that herbicides may also play a role in the development of suppression because of the "greenbridge" effect on soilborne pathogens (Babiker et al. 2011). Although many root pathogens persist in soil by colonizing dying roots of crops and weeds, what about the microbial communities that eventually displace these pathogens on the root? Can they serve as a source of suppression? Recent work by D. C. Schlatter, C. Yin, S. Hulbert, I. Burke, and T. C. Paulitz (unpublished data) has described bacterial communities associated with roots killed by glyphosate. They showed that specific bacterial OTUs are enriched on roots in pots treated with multiple cycles of glyphosate, and more OTUs are increased by glyphosate than are reduced. Can herbicide timing be part of establishing suppressive populations?

Cover crops and green manures promoted by the National Resource Conservation Service of the U.S. Department of Agriculture are touted as an important part of soil health. They are being used increasingly, especially in wetter areas of the U.S. Midwest and South than in the more arid dryland regions. These practices are designed to maintain a cover year-round to prevent soil erosion, increase organic matter, and improve soil structure by fostering deeper taproots that can break up tillage pans. Can these crops, as drivers of soil microbial communities, influence the development of soil suppressiveness?

The use of substrate amendments to enhance general suppression in perennial and other high-value crops has been explored recently by Mazzola and Freilich (2017). For example, the addition of brassica seed meals has been shown to be a biologically based and effective management practice for apple replant disease (Mazzola et al. 2007, 2015; Weerakoon et al. 2012). Similarly, the use of a substrate to shift microbial communities is employed in anaerobic soil disinfestation (ASD), in which organic substrates are added to soil and then flooded to produce oxygen stress and stimulate anaerobic communities that produce organic acids and alcohols suppressive to pathogens (Hewavitharana and Mazzola 2016; Hewavitharana et al. 2014).

Breeding crop varieties that promote beneficial microbial communities is the approach with perhaps the greatest potential impact. There is increasing evidence that the cultivar can influence the composition of the rhizosphere microbial community (Weller 1986). Mahoney et al. (2017) showed that the cultivars differentially selected soil bacteria, some of which provided potential benefits to the host such as pathogen suppression or nutrient mobilization. The development of cultivars selective for suppressive or biocontrol communities in the rhizosphere has long been a dream for plant breeding, but until now we have lacked the tools to attempt it (Bakker et al. 2012; Raaijmakers and Mazzola 2016). The more we understand about the complex microbial interactions involved in disease suppression, the greater the chances of melding this information with host plant breeding strategies and specific grower practices and recommendations supportive of greater crop productivity.

\section{LITERATURE CITED}

Achouak, W., Sutra, L., Heulin, T., Meyer, J.-M., Fromin, N., Degraeve, S., Christen, R., and Gardan, L. 2000. Pseudomonas brassicacearum sp. nov. and Pseudomonas thivervalensis sp. nov, two root-associated bacteria from Brassica napus and Arabidopsis thaliana. Int. J. Syst. Bacteriol. Evol. Microbiol. 50:9-18.

Al-Ghalith, G. A., Montassier, E., Ward, H. N., and Knights, D. 2016. NINJAOPS: Fast accurate marker gene alignment using concatenated ribosomes. PLOS Comput. Biol. 12:e1004658.

Alabouvette, C. 1986. Fusarium wilt-suppressive soils from the Chateaurenard region: Review of a 10-year study. Agronomie 6:273-284.

Allende-Molar, R. 2006. Role of 2,4-diacetylphloroglucinol-producing Pseudomonas fluorescens in the suppression of take-all and Pythium root rot of wheat. Ph.D. Thesis, Washington State University, Pullman.

Anees, M., Tronsom, A., Edel-Hermann, V., Gautheron, N., Faloya, V., and Steinberg, C. 2010. Biotic changes in relation to local decrease in soil conduciveness to disease caused by Rhizoctonia solani. Eur. J. Plant Pathol. 126:29-41.

Babiker, E. M., Hulbert, S. H., Schroeder, K. L., and Paulitz, T. C. 2011. Optimum timing of preplant applications of glyphosate to manage Rhizoctonia root rot in barley. Plant Dis. 95:304-310.

Baker, K. F., and Cook, R. J. 1974. Biological Control of Plant Pathogens. Freeman, San Francisco, CA

Bakker, M. G., Manter, D. K., Sheflin, A. M., Weir, T. L., and Vivanco, J. M. 2012. Harnessing the rhizosphere microbiome through plant breeding and agricultural management. Plant Soil 360:1-13.

Bakker, M. G., Otto-Hanson, L., Lange, A. J., Bradeen, J. M., and Kinkel, L. L. 2013. Plant monocultures produce more antagonistic soil Streptomyces communities than high-diversity plant communities. Soil Biol. Biochem. 65:304-312.

Barnett, S. J., Roget, D. K., and Ryder, M. H. 2006. Suppression of Rhizoctonia solani AG-8 induced disease on wheat by the interaction between Pantoea, Exiguobacterium, and Microbacteria. Aust. J. Soil Res. 44:331-342.

Becker, D. M., Kinkel, L. L., and Schottel, J. L. 1997. Evidence for interspecies communication and its potential role in pathogen suppression in a naturally-occurring disease suppressive soil. Can. J. Microbiol. 43:985-990.

Belimov, A. A., Dodd, I. C., Safronava, V. I., Hontzeas, N., and Davies, W. J. 2007. Pseudomonas brassicacearum strain Am3 containing 1aminocyclopropane-1-carboxylate deaminase can show both pathogenic and growth-promoting properties in its interaction with tomato. J. Exp. Bot. 58:1485-1495.

Bergsma-Vlami, M., Prins, M. E., Staats, M., and Raaijmakers, J. M. 2005. Assessment of genotypic diversity of antibiotic-producing Pseudomonas species in the rhizosphere by denaturing gradient gel electrophoresis. Appl. Environ. Microbiol. 71:993-1003.

Bignell, D. R., Fyans, J. K., and Cheng, Z. 2014. Phytotoxins produced by plant pathogenic Streptomyces species. J. Appl. Microbiol. 116:223-235.

Bignell, D. R., Huguet-Tapia, J. C., Joshi, M. V., Pettis, G. S., and Loria, R. 2010. What does it take to be a plant pathogen: Genomic insights from Streptomyces species. Antonie van Leeuwenhoek 98:179-194.

Bonanomi, G., Antignani, V., Capodilupo, M., and Scala, F. 2010. Identifying the characteristics of organic soil amendments that suppress soilborne plant diseases. Soil Biol. Biochem. 42:136-144.

Bowers, J. H., Kinkel, L. L., and Jones, R. K. 1996. Influence of diseasesuppressive strains of Streptomyces on the native Streptomyces community in soil as determined by the analysis of cellular fatty acids. Can. J. Microbiol. 42:27-37.

Brooks, J. P., Edwards, D. J., Harwich, M. D., Rivera, M. C., Fettweis, J. M., Serrano, M. G., Reris, R. A., Sheth, N. U., Huang, B., Girerd, P., Vaginal Microbiome Consortium, Strauss, J. F., III, Jefferson, K. K., and Buck, G. A. 2015. The truth about metagenomics: Quantifying and counteracting bias in 16S rRNA studies. BMC Microbiol. 15:66.

Callahan, B. J., McMurdie, P. J., Rosen, M. J., Han, A. W., Johnson, A. J. A., and Holmes, S. P. 2016. DADA2: High-resolution sample inference from Illumina amplicon data. Nat. Methods 13:581-583.

Cao, L., Qui, Z., You, J., Tan, H., and Zhou, S. 2004. Isolation and characterization of endophytic Streptomyces strains from surface-sterilized tomato (Lycopersicon esculentum) roots. Lett. Appl. Microbiol. 39:425-430. 
Carling, D. E., Kuninaga, S., and Brainard, K. A. 2002. Hyphal anastomosis reactions, rDNA-internal transcribed spacer sequences, and virulence levels among subsets of Rhizoctonia solani anastomosis group-2 (AG-2) and AGBI. Phytopathology 92:43-50.

Cha, J., Han, S., Hong, H., Cho, H., Kim, D., Kwon, Y. 2016. Microbial and biochemical basis of a Fusarium wilt-suppressive soil. ISME J. 10: $119-129$

Chapelle, E., Mendes, R., Bakker, P. A. H. M., and Raaijmakers, J. M. 2016. Fungal invasion of the rhizosphere microbiome. ISME J. 10:265-268.

Chater, K. F., Biro, S., Lee, K. J., Palmer, T., and Schrempf, H. 2010. The complex extracellular biology of Streptomyces. FEMS Microbiol. Rev. 34: 171-198.

Cook, R. J. 2003. Take-all of wheat. Physiol. Mol. Plant Pathol. 62:73-86.

Cook, R. J. 2007. Take-all decline: A model system in biological control and clue to the success of intensive cropping. Pages 399-414 in: Biological Control a Global Perspective: Case Studies from Around the World. C. Vincent, M. Goettel, and G. Lazarovits, eds. CABI Publishing, U.K.

Cook, R. J. 2014. Plant health management: Pathogen suppressive soils. Pages 441-455 in: Encyclopedia of Agriculture and Food Systems. Elsevier, Amsterdam, Netherlands.

Cook, R. J., and Baker, K. F. 1983. The Nature and Practice of Biological Control of Plant Pathogens. American Phytopathological Society, St. Paul, $\mathrm{MN}$

Cook, R. J., and Rovira, A. D. 1976. The role of bacteria in the biological control of Gaeumannomyces graminis by suppressive soils. Soil Biol. Biochem. 8:269-273.

Coyotzi, S., Pratscher, J., Murrell, J. C., and Neufeld, J. D. 2016. Targeted metagenomics of active microbial populations with stable-isotope probing. Curr. Opin. Biotechnol. 41:1-8.

De La Fuente, L., Mavrodi, D. V., Landa, B. B., Thomashow, L. S., and Weller, D. M. 2006. phlD-based genetic diversity and detection of genotypes of 2,4diacetylpholorogucinol-producing Pseudomonas fluorescens. FEMS Microbiol. Ecol. 56:64-78.

de Souza, J. T., Weller, D. M., and Raaijmakers, J. M. 2003. Frequency, diversity, and activity of 2,4-diacetylphloroglucinol-producing fluorescent Pseudomonas spp. in Dutch take-all decline soils. Phytopathology 93: 54-63.

Donn, S., Almario, J., Muller, D., Moēnne-Loccoz, Y., Gupta, V. V. S. R., Kirkegaard, J., and Richardson, A. E. 2014. Rhizosphere microbial communities associated with Rhizoctonia damage at the field and disease patch. Appl. Soil Ecol. 78:37-47.

Edgar, R. C. 2016. UNOISE2: Improved error-correction for Illumina 16S and ITS amplicon sequencing. bioRxiv 081257. doi: https://doi.org/10.1101/081257

Essarioui, A., Kistler, H. C., and Kinkel, L. L. 2016. Nutrient use preferences among soil Streptomyces suggest greater resource competition in monoculture than polyculture plant communities. Plant Soil 409:329-343.

Franco, C. M. M., Araujo, R., Adetutu, E., Tobe, S. S., Mallya, S., Paul, B., and Satyamoorthy, K. 2016. Complete genome sequences of the endophytic Streptomyces strains EN16, EN23, and EN27, isolated from wheat plants. Genome Announc. 4:e1342-16.

Frapolli, M., Moëenne-Loccoz, Y., Meyer, J., and Défago, G. 2008. A new DGGE protocol targeting 2,4-diacetylphloroglucinol biosynthetic gene phlD from phylogenetically contrasted biocontrol pseudomonads for assessment of disease-suppressive soils. FEMS Microbiol. Ecol. 64:468-481.

Freeman, J., and Ward, E. 2004. Gaeumannomyces graminis, the take-all fungus and its relatives. Mol. Plant Pathol. 5:235-252.

Gerlagh, M. 1968. Introduction of Ophiobolus graminis into new polders and its decline. Neth. J. Plant Pathol. 74:1-97.

Gupta, V. V. S. R. N. S. M., and Dumitrescu, I. 1999. Effects of microfauna and mesofauna on Rhizoctonia solani in a south Australian soil. Pages 134-136 in: Proceedings of the First Australasian Soilborne Disease Symposium. R. C. Magarey, ed. BSES, Brisbane, Australia.

Haney, R. L., Kiniry, J. R., and Johnson, M.-V. V. 2010. Soil microbial activity under different grass species: underground impacts of biofuel cropping. Agric. Ecosyst. Environ. 139:754-758.

He, Y., Caporaso, J. G., Jiang, X. T., Sheng, H. F., Huse, S. M., Rideout, J. R., Edgar, R. C., Kopylova, E., Walters, W. A., Knight, R., and Zhou, H. W. 2015. Stability of operational taxonomic units: An important but neglected property for analyzing microbial diversity. Microbiome 3:20.

Hewavitharana, S. S., and Mazzola, M. 2016. Carbon source-dependent effects of anaerobic soil disinfestation on soil microbiome and suppression of Rhizoctonia solani AG-5 and Pratylenchus penetrans. Phytopathology 106: 1015-1028.

Hewavitharana, S. S., Rudell, D., and Mazzola, M. 2014. Carbon sourcedependent antifungal and nematicidal volatiles derived during anaerobic soil disinfestation. Eur. J. Plant Pathol. 140:39-52.

Hiltunen, L. H., Ojanperä, T., Kortemaa, H., Richter, E., Lehtonen, M. J., and Valkonen, J. P. T. 2009. Interactions and biocontrol of pathogenic Strep- tomyces strains co-occurring in potato scab lesions. J. Appl. Microbiol. 106: 199-212

Hjort, K., Bergström, M., Adesina, M. F., Jansson, J. K., Smalla, K., and Sjöling, S. 2010. Chitinase genes revealed and compared in bacterial isolates, DNA extracts and a metagenomic library from a phytopathogensuppressive soil. FEMS Microbiol. Ecol. 71:197-207.

Hornby, D. 1983. Suppressive soils. Annu. Rev. Phytopathol. 21:65-85.

Hornby, D. 1998. Take-all of Cereals: A Regional Perspective. CAB International, Wallingford, U.K

Howe, A. C., Jansson, J. K., Malfatti, S. A., Tringe, S. G., Tiedje, J. M., and Brown, C. T. 2014. Tackling soil diversity with the assembly of large, complex, metagenomes. Proc. Natl. Acad. Sci. USA 111:4904-4909.

Jiang, Y., Xiong, X., Danska, J., and Parkinson, J. 2016. Metatranscriptomic analysis of diverse microbial communities reveals core metabolic pathways and microbiome-specific functionality. Microbiome 4:2.

Kembel, S. W., Wu, M., Eisen, J. A., and Green, J. L. 2012. Incorporation 16S gene copy number information improves estimates of microbial diversity and abundance. PLOS Comput. Biol. 8:e1002743.

Kennedy, K., Hall, M. W., Lynch, M. D. J., Moreno-Hagelsieb, G., and Neufeld, J. D. 2014. Evaluating bais of Illumina-based bacterial 16S rRNA gene profiles. Appl. Environ. Microbiol. 80:5717-5722.

Kieser, T., Chater, K. F., Bibb, M. J., Buttner, M. J., and Hopwood, D. A. 2000. Practical Streptomyces. Genetics. John Innes Foundation, U.K.

Kinkel, L. L., Bakker, M. G., and Schlatter, D. C. 2011. A coevolutionary framework for managing disease-suppressive soils. Annu. Rev. Phytopathol. 49:47-67.

Kinkel, L. L., Schlatter, D. C., Bakker, M. G., and Arenz, B. E. 2012. Streptomyces competition and co-evolution in relation to plant disease suppression. Res. Microbiol. 163:490-499.

Kinkel, L. L., Schlatter, D. C., Xiao, K., and Baines, A. D. 2014. Sympatric inhibition and niche differentiation suggest alternative coevolutionary trajectories among Streptomycetes. ISME J. 8:249-256

Klein, E., Ofek, M., Katan, J., Minz, D., and Gamlie, A. 2013. Soil suppressiveness to Fusarium disease: Shifts in root microbiome associated with reduction of pathogen root colonization. Phytopathology 103:23-33.

Kopylova, E., Navas-Molina, J. A., Mercier, C., Xu, Z. Z., Mahe, F., He, Y., Zhou, H. W., Rognes, T., Caporaso, J. G., and Knight, R. 2016. Open-source sequence clustering methods improve the state of the art. mSystems 1:e00003-15.

Kuske, C. R., Hesse, C. N., Challacombe, J. F., Cullen, D., Herr, J. R., Mueller, R. C., Tsang, A., and Vilgalys, R. 2015. Prospects and challenges for fungal metatranscriptomics of complex communities. Fungal Ecol. 14:133-137.

Kwak, Y.-S., Bakker, P. A. H. M., Glandorf, D. C. M., Rice, J. T., Paulitz, T. C., and Weller, D. M. 2009. Diversity, virulence and 2,4-diacetylphloroglucinol sensitivity of Gaeumannomyces graminis var. tritici isolates from Washington State. Phytopathology 99:472-479.

Kwak, Y.-S., Bonsall, R. F., Okubara, P. A., Paulitz, T. C., Thomashow, L. S., and Weller, D. M. 2012. Factors impacting the activity of 2,4diacetylphloroglucinol-producing Pseudomonas fluorescens against take-all of wheat. Soil Biol. Biochem. 54:48-56.

Kwak, Y.-S., Han, S., Thomashow, L. S., Rice, J. T., Paulitz, T. C., Kim, D., and Weller, D. M. 2011. Saccharomyces cerevisiae genome-wide mutant screen for sensitivity to 2,4-diacetylphloroglucinol, an antibiotic produced by Pseudomonas fluorescens. Appl. Environ. Microbiol. 77:1770-1776.

Kwak, Y.-S., and Weller, D. M. 2012. Take-all of wheat and natural disease suppression. J. Plant Pathol. 29:125-135.

Lamovšek, J., Stare, B. G., and Urek, G. 2014. Isolation of non-pathogenic Agrobacterium spp. biovar 1 from agricultural soils in Slovenia. Phytopathol. Mediterr. 53:130-139.

Landa, B. B., Mavrodi, D. V., Thomshow, L. S., and Weller, D. M. 2003. Interactions between strains of 2,4-diacetylphloroglucinol-producing Pseudomonas fluorescens in the rhizosphere of wheat. Phytopathology 93:982-994.

Landa, B. B., Mavrodi, O. V., Raaijmakers, J. M., Gardener, B. B. M., Thomashow, L. S., and Weller, D. M. 2002. Differential ability of genotypes of 2,4-diacetylphloroglucinol-producing Pseudomonas fluorescens strains to colonize the roots of pea plants. Appl. Environ. Microbiol. 68:3226-3237.

Landa, B. B., Mavrodi, O. V., Schroeder, K. L., Allende-Molar, R., and Weller, D. M. 2006. Enrichment and genotypic diversity of phlD-containing fluorescent Pseudomonas spp. in two soils after a century of wheat and flax monoculture. FEMS Microbiol. Ecol. 55:351-368.

Lerat, S., Simao-Beaunoir, A. M., and Beaulieu, C. 2009. Genetic and physiological determinants of Streptomyces scabies pathogenicity. Mol. Plant Pathol. 10:579-585.

Liu, D., Anderson, N. A., and Kinkel, L. L. 1995. Biological control of potato scab in the field with antagonistic Streptomyces scabies. Phytopathology 85:827-831

Liu, D., Anderson, N. A., and Kinkel, L. L. 1996. Selection and characterization of strains of Streptomyces suppressive to the potato scab pathogen. Can. J. Microbiol. 42:487-502. 
Loper, J. E., Hassan, K. A., Mavrodi, D. V., Davis, E. W., II, Lim, C. K., and Shaffer, B. T. 2012. Comparative genomics of plant-associated Pseudomonas spp.: Insights into diversity and inheritance of traits involved in multitrophic interactions. PLoS Genet. 8:e1002784.

Lorang, J. M., Anderson, N. A., Lauer, F. I., and Wildung, D. K. 1989. Disease decline in a Minnesota potato scab plot. Am. Potato J. 66:531.

Loria, R., Kers, J., and Joshi, M. 2006. Evolution of plant pathogenicity in Streptomyces. Annu. Rev. Phytopathol. 44:469-87.

MacNish, G. C. 1988. Changes in take-all (Gaeumannomyces graminis var. tritici), Rhizoctonia root rot (Rhizoctonia solani) and soil $\mathrm{pH}$ in continuous wheat with annual applications of nitrogenous fertilizer in Western Australia. Aust. J. Exp. Agric. 28:333-341.

MacNish, G. C., and Neate, S. M. 1996. Rhizoctonia bare patch of cereals-An Australian perspective. Plant Dis. 80:965-997.

Mahoney, A. K., Yin, C., and Hulbert, S. H. 2017. Community structure, species variation, and potential functions of rhizosphere-associated bacteria of different winter wheat (Triticum aestivum) cultivars. Front. Plant Sci. 8:132.

Maketon, C., Fortuna, A.-M., and Okubara, P. A. 2012. Cultivar-dependent transcript accumulation in wheat roots colonized by Pseudomonas fluorescens Q8r1-96 wild type and mutant strains. Biol. Control 60:216-224.

Mavrodi, O. V., Mavrodi, D. V., Parejko, J. A., Thomashow, L. S., and Weller, D. M. 2012. Irrigation differentially impacts populations of indigenous antibiotic-producing Pseudomonas spp. in the rhizosphere of wheat. Appl. Environ. Microbiol. 78:3214-3220.

Mazzola, M. 2007. Manipulation of rhizosphere bacterial communities to induce suppressive soils. J. Nematol. 39:213-220.

Mazzola, M., Brown, J., Izzo, A. D., and Cohen, M. F. 2007. Mechanism of action and efficacy of seed meal-induced pathogen suppression differ in a Brassicaceae species and time-dependent manner. Phytopathology 97: 454-460.

Mazzola, M., and Freilich, S. 2017. Prospects for biological soilborne disease control: Application of indigenous versus synthetic microbiomes. Phytopathology 107:256-263.

Mazzola, M., Fujimoto, D. K., Thomashow, L. S., and Cook, R. J. 1995. Variation in sensitivity of Gaeumannomyces graminis to antibiotics produced by fluorescent Pseudomonas spp. and effect on biological control of take-all of wheat. Appl. Environ. Microbiol. 61:2254-2559.

Mazzola, M., Funnell, D. L., and Raaijmakers, J. M. 2004. Wheat cultivarspecific selection of 2,4-diacetylphloroglucinol-producing Pseudomonas species from resident soil populations. Microbiol. Ecol. 48:338-348.

Mazzola, M., Hewavitharana, S., and Strauss, S. L. 2015. Brassica seed meal soil amendments transform the rhizosphere microbiome and improve apple production through resistance to pathogen re-infestation. Phytopathology 105:460-469.

McMillan, V. E., Hammond-Kosack, K. E., and Gutteridge, R. J. 2011. Evidence that wheat cultivars differ in their ability to build up inoculum of the take-all fungus, Gaeumannomyces graminis var. tritici, under a first wheat crop. Plant Pathol. 60:200-206.

McMurdie, P. J., and Holmes, S. 2014. Waste not, want not: Why rarefying microbiome data is inadmissible. PLOS Comput. Biol. 10:e1003531.

McSpadden Gardener, B. B., Gutierrez, L. J., Raghavendra, J., Edema, R., and Lutton, E. 2005. Distribution and biocontrol potential of $p h l D^{+}$pseudomonads in corn and soybean fields. Phytopathology 95:715-724.

McSpadden Gardener, B. B., Schroeder, K. L., Kalloger, S. E., Raaijmakers, J. M., Thomashow, L. S., and Weller, D. M. 2000. Genotypic and phenotypic diversity of phlD-containing Pseudomonas isolated from the rhizosphere of wheat. Appl. Environ. Microbiol. 66:1939-1946.

Mendes, R., Kruijt, M., deBruijn, I., Dekkers, E., and van derVoort, M. 2011. Deciphering the rhizosphere microbiome for disease-suppressive bacteria. Science 332:1097-1100.

Meng, Q. X., Yin, J. F., Rosenzweig, N., Douches, D., and Hao, J. J. 2012. Culture-based assessment of microbial communities in soil suppressive to potato common scab. Plant Dis. 96:712-717.

Menzies, J. D. 1959. Occurrence and transfer of a biological factor in soil that suppresses potato scab. Phytopathology 49:648-652.

Neeno-Eckwall, E. C., Kinkel, L. L., and Schottel, J. L. 2001. Competition and antibiosis in the biological control of potato scab. Can. J. Microbiol. 47: 332-340.

New, P. B., and Kerr, A. 1972. Biological control of crown gall: Field measurements and glasshouse experiments. J. Appl. Bacteriol. 35:279-287.

Nguyen, N. H., Smith, D., Peay, K., and Kennedy, P. 2015. Parsing ecological signal from noise in next generation amplicon sequencing. New Phytol. 205:1389-1393.

Nguyen, N. P., Warnow, T., Pop, M., and White, B. 2016. A perspective on 16S rRNA operational taxonomic unit clustering using sequence similarity. NPJ Biofilms and Microbiomes 2:16004.

Notz, R., Maurhofer, M., Schnider-Keel, U., Duffy, B., Haas, D., and Défago, G. 2001. Biotic factors affecting expression of the 2,4-diacetylphlor- oglucinol biosynthesis gene phlA in Pseudomonas fluorescens biocontrol strain CHA0 in the rhizosphere. Phytopathology 91:873-881.

Olatinwo, R., Yin, B., Becker, J. O., and Borneman, J. 2006. Suppression of the plant-parasitic nematode Heterodera schachtii by the fungus Dactylella oviparasitica. Phytopathology 96:111-114.

Paulitz, T. C., Schillinger, W. F., and Cook, R. J. 2003. Greenhouse studies of Rhizoctonia bare patch disease in soil cores from direct-seeded fields. American Society of Agronomy Annual Meeting, Denver, CO.

Paulitz, T. C., Smiley, R. W., and Cook, R. J. 2002. Insights into the prevalence and management of soilborne cereal pathogens under direct seeding in the Pacific Northwest, U.S.A. Can. J. Plant Pathol. 24:416-428.

Paulitz, T. C., Yin, C., Hulbert, S., Schroeder, K., Schillinger, W., Mavrodi, O., Mavrodi, D., Kirkegaard, J., and Gupta, V. V. S. R. 2012. Role of microbial communities in the natural suppression of Rhizoctonia bare patch of wheat in the USA and Australia. The 7th Australasian Soilborne Diseases Symposium, Freemantle, WA.

Paulson, J. N., Stine, O. C., Bravo, H. C., and Pop, M. 2013. Robust methods for differential abundance analysis in marker gene surveys. Nat. Methods 10:1200-1202.

Penton, C. R., Gupta, V. V. S. R., Tiedje, J. M., Neate, S. M., Ophel-Keller, K., Gillings, M., Harvey, P., Pham, A., and Roget, D. K. 2014. Fungal community structure in disease suppressive soils assessed by 28S LSU gene sequencing. PLoS One 9:e93893.

Picard, C., and Bosco, M. 2003. Genetic diversity of phlD gene from 2,4diacetylphloroglucinol-producing Pseudomonas spp. strains from the maize rhizosphere. FEMS Microbiol. Lett. 219:167-172.

Postma, J., Scheper, R. W. A., and Schilder, M. T. 2010. Effect of successive cauliflower plantings and Rhizoctonia solani AG 2-1 inoculations on disease suppressiveness of a suppressive and a conducive soil. Soil Biol. Biochem. 42:804-812.

Poudel, R., Jumpponen, A., Schlatter, D. C., Paulitz, T. C., McSpadden Gardener, B. B., Kinkel, L. L., and Garrett, K. A. 2016. Microbiome networks: A systems framework for identifying candidate microbial assemblages for disease management. Phytopathology 106:1083-1096.

Prosser, J. I. 2015. Dispersion misconceptions and identifying opportunities for the use of 'omics' in soil microbial ecology. Nat. Rev. Microbiol. 13: 439-446.

Raaijmakers, J. M., Bonsall, R. F., and Weller, D. M. 1999. Effect of population density of Pseudomonas fluorescens on production of 2,4diacetylphloroglucinol in the rhizosphere of wheat. Phytopathology 89:470-475.

Raaijmakers, J. M., and Mazzola, M. 2016. Soil immune responses: Soil microbiomes may be harassed for plant health. Science 352:1392-1393.

Raaijmakers, J. M., and Weller, D. M. 1998. Natural plant protection by 2,4diacetylphloroglucinol-producing Pseudomonas spp. in take-all decline soils. Mol. Plant-Microbe Interact. 11:144-152.

Raaijmakers, J. M., and Weller, D. M. 2001. Exploiting genotypic diversity of 2,4-diacetylphloroglucinol-producing Pseudomonas spp.: Characterization of superior root-colonizing P. fluorescens strain Q8r1-96. Appl. Environ. Microbiol. 67:2545-2554

Raaijmakers, J. M., Weller, D. M., and Thomashow, L. S. 1997. Frequency of antibiotic-producing Pseudomonas spp. in natural environments. Appl. Environ. Microbiol. 63:881-887.

Roget, D. K., and Coppi, J. A., Herdina, and Gupta, V. V. S. R. 1999. Assessment of suppression to Rhizoctonia solani in a range of soils across SE Australia. Proceedings of the First Australasian Soilborne Disease Symposium, Brisbane, Australia.

Rognes, T., Flouri, T., Quince, C., and Mahe, F. 2016. VSEARCH: A versatile open source tool for metagenomics. PeerJ 4:e2584.

Rosenzweig, N., Tiedje, J. M., Quensen, J. F., Meng, Q., and Hao, J. J. 2012. Microbial communities associated with potato common scab-suppressive soil determined by pyrosequencing analyses. Plant Dis. 96:718-725.

Ryan, A. D., and Kinkel, L. L. 1997. Inoculum density and population dynamics of suppressive and pathogenic Streptomyces strains and their relationship to biological control of potato scab. Biol. Control 10:180-186.

Sadeghpour, A., Ketterings, Q. M., Vermeylen, F., Godwin, G. S., and Czymmek, K. J. 2016. Soil properties under nitrogen- vs. phosphorus-based manure and compost management of corn. Soil Sci. Soc. Am. J. 80:1272-1282.

Salter, S. J., Cox, M. J., Turek, E. M., Calus, S. T., Cookson, W. O., Moffatt, M. F., Turner, P., Parkhill, J., Loman, N. J., and Walker, A. W. 2014. Reagent and laboratory contamination can critically impact sequence-based microbiome analyses. BMC Biol. 12:87.

Sanguin, H., Sarniquet, A., Gazengel, K., Moënne-Loccoz, Y., and Grundmann, G. L. 2009. Rhizosphere bacterial communities associated with disease suppressive stages of take-all decline in wheat monoculture. New Phytol. 184:694-707.

Sagova-Mareckova, M., Daniel, O., Omelka, M., Kristufek, V., Divis, J., and Kopecky, J. 2015. Determination of factors associated with natural soil suppressivity to potato common scab. PLoS One 10:e0116291. 
Schillinger, W. F., and Paulitz, T. C. 2014. Natural suppression of Rhizoctonia bare patch in a long-term no-till cropping systems experiment. Plant Dis. 98:389-394.

Schlatter, D. C., Bakker, M. G., Bradeen, J. M., and Kinkel, L. L. 2015. Plant community richness and microbial interactions structure bacterial communities in soil. Ecology 96:134-142.

Schloss, P. D., Jenior, M. L., Koumpouras, C. C., Westcott, S. L., and Highlander, S. K. 2016. Sequencing 16S rRNA gene fragments using PacBio SMRT DNA sequencing system. Peer J. PrePrints 4:e1869.

Schrey, S. D., and Tarkka, M. T. 2008. Friends and foes: Streptomycetes as modulators of plant disease and symbiosis. Antonie van Leeuwenhoek 94:11-9.

Seipke, R. F., Kaltenpoth, M., and Hutchings, M. I. 2012. Streptomyces as symbionts: An emerging and widespread theme? FEMS Microbiol. Rev. 36: 862-876.

Sekar, J., and Prabavathy, V. R. 2014. Novel Phl-producing genotypes of finger millet rhizosphere associated pseudomonads and assessment of their functional and genetic diversity. FEMS Microbiol. Ecol. 89:32-46.

Sharpton, T. J. 2014. An introduction to the analysis of shotgun metagenomics data. Front. Plant Sci. 5:209.

Shipton, P. J. 1975. Take-all decline during cereal monoculture. Pages 137-144 in: Biology and Control of Soil-Borne Plant Pathogens. G. W. Bruehl, ed. American Phytopathological Society, St. Paul, MN.

Sikorski, J., Jahr, H., and Wackernagel, W. 2001. The structure of a local population of phytopathogenic Pseudomonas brassicacearum from agricultural soil indicates development under purifying selection pressure. Environ. Microbiol. 3:176-186.

Song, Z., Schlatter, D., Kennedy, P., Kinkel, L. L., Kistler, H. C., Nguyen, N., and Bates, S. T. 2015. Effort versus reward: Preparing samples for fungal community characterization in high-throughput sequencing surveys of soils. PLoS One 10:e0127234.

Takano, E. 2006. Y-butyrolactones: Streptomyces signaling molecules regulating antibiotic production and differentiation. Curr. Opin. Microbiol. 9:287-294.

Thorsen, J., Brejnrod, A., Mortensen, M., Rasmussen, M. A., Stokholm, J., Al-Soud, W. A., Sorensen, S., Bisgaard, H., and Waage, J. 2016. Largescale benchmarking reveals false discoveries and count transformation sensitivity in 16S rRNA gene amplicon data analysis methods used in microbiome studies. Microbiome 4:62.

Tomihama, T., Nishi, Y., Mori, K., Shirao, T., Iida, T., Uzuhashi, S., Ohkuma, M., and Ikeda, S. 2016. Rice bran amendment suppresses potato common scab by increasing antagonistic bacterial community levels in the rhizosphere. Phytopathology 106:719-728.

Traxler, M. F., Watrous, J. D., Alexandrov, T., Dorrestein, P. C., and Kolter, R. 2013. Interspecies interactions stimulate diversification of the Streptomyces coelicolor secreted metabolome. MBio 4:e00459-13.

Ueda, K., Kawai, S., Ogawa, H., Kiyama, A., Kubota, T., Kawanobe, H., and Beppu, T. 2000. Wide distribution of interspecific stimulatory events on antibiotic production and sporulation among Streptomyces species. J. Antibiot. 53:979-982.

Viaene, T., Langendries, S., Beirinckx, S., Maes, M., and Goormachtig, S. 2016. Streptomyces as a plant's best friend? FEMS Microbiol. Ecol. 92

Wang, W., Ji, J., Li, X., Wang, J., Li, S., Pan, G., Fan, K., and Yang, K. 2014. Angucyclines as signals modulate the behaviors of Streptomyces coelicolor. Proc. Natl. Acad. Sci. USA 111:5866-5693.
Wanner, L. A. 2007. High proportions of nonpathogenic Streptomyces are associated with common scab-resistant potato lines and less severe disease. Can. J. Microbiol. 53:1062-1075.

Watve, M. G., Tickoo, R., Jog, M. M. 2001. How many antibiotics are produced by the genus Streptomyces? Arch. Microbiol. 176:386.

Weerakoon, D. M. N., Reardon, C. L., Paulitz, T. C., Izzo, A. D., and Mazzola, M. 2012. Long-term suppression of Pythium abappressorium induced by Brassica juncea seed meal amendment is biologically mediated. Soil Biol. Biochem. 51:44-52.

Weinhold, A. R., and Bowman, T. 1968. Selective inhibition of the potato scab pathogen by antagonistic bacteria and substrate influence on antibiotic production. Plant Soil 28:12-24.

Weiss, S. J., Xu, Z., Amir, A., Peddada, S., Bittinger, K., Gonzalez, A., Lozupone, C., Zaneveld, J. R., Vazquez-Baeza, Y., Birmingham, A., and Knight, R. 2015. Effects of library size variance, sparsity, and compositionality on the analysis of microbiome data. PeerJ. 3:e1157v1. https://peerj.com/ preprints/1157v1/

Weller, D. M. 1986. Effects of wheat genotype on root colonization by a takeall suppressive strain of Pseudomonas fluorescens. Phytopathology 76: 1059.

Weller, D. M. 2015. Take-all decline and beneficial pseudomonads. Pages 363-370 in: Principles of Plant-Microbe Interactions-Microbes for Sustainable Agriculture. B. Lugtenberg, ed. Springer, Switzerland.

Weller, D. M., Cook, R. J., MacNish, G., Bassett, E. N., Powelson, R. L., and Petersen, R. R. 1986. Rhizoctonia root rot of small grains favored by reduced tillage in the Pacific Northwest. Plant Dis. 70:70-73.

Weller, D. M., Landa, B. B., Mavrodi, O. V., Schroeder, K. L., De La Fuente, L., Blouin Bankhead, S., Allende Molar, R., Bonsall, R. F., Mavrodi, D. V., and Thomashow, L. S. 2007. Role of 2,4-diacetylphloroglucinol-producing fluorescent Pseudomonas spp. in the defense of plant roots. Plant Biol. 9: 4-20.

Weller, D. M., Raaijmakers, J. M., McSpadden Gardener, B. B., and Thomashow, L. S. 2002. Microbial populations responsible for specific suppressiveness to plant pathogens. Annu. Rev. Phytopathol. 40: 309-348.

Wiggins, B. E., and Kinkel, L. L. 2005a. Green manures and crop sequences influence alfalfa root rot and pathogen inhibitory activity among soil-borne streptomycetes. Plant Soil 268:271-283.

Wiggins, B. E., and Kinkel, L. L. 2005b. Green manures and crop sequences influence potato diseases and pathogen inhibitory activity of indigenous streptomycetes. Phytopathology 95:178-185

Williams, D. H., Stone, M. J., Hauck, P. R., and Rahman, S. K. 1989. Why are secondary metabolites (natural products) biosynthesized? J. Nat. Prod. 52:1189-208.

Wiseman, B. M., Neate, S. M., Keller, K. O., and Smith, S. E. 1996. Suppression of Rhizoctonia solani anastomosis group 8 in Australia and its biological nature. Soil Biol. Biochem. 28:727-732.

Yin, C., Hulbert, S., Schroeder, K., Mavrodi, O., Mavrodi, D., Schillinger, W., and Paulitz, T. C. 2013. The role of bacterial communities in the natural suppression of Rhizoctonia bare patch of wheat. Appl. Environ. Microbiol. 79:7428-7438.

Zhou, J., He, Z., Yang, Y., Deng, Y., Tringe, S. G., and Alvarez-Cohen, L. 2015. High-throughput metagenomics technologies for complex microbial community analysis: Open and closed formats. MBio 6:e02288-14. 